\title{
VII. Aufenthaltsverbot in Frankreich
}

\author{
1. Apaisement oder Konfrontation: \\ Trügerische Ruhe im Winterhalbjahr 1938/39
}

Unter dem Gesichtspunkt, daß sich nur das legitime Selbstbestimmungsrecht der Völker Bahn breche, vermochte Otto Abetz auch die Einverleibung der sudetendeutschen Gebiete ins Reich zu rechtfertigen. Beglückt registrierte er die Reaktion der Pariser Bevölkerung, die Ministerpräsident Daladier bei seiner Rückkehr von der Münchener Konferenz (29./30. September) einen triumphalen Empfang bereitete. Aus Abetz' Blickwinkel handelte es sich um die "machtvollste Manifestation des Friedens- und Verständigungswillens, welche die französische Hauptstadt je in ihren Mauern gesehen hatte"1. Euphorisch verkündeten die Deutsch-Französischen Monatshefte, die Flamme des Krieges sei ausgetreten worden ${ }^{2}$. Abetz beschwor voller Pathos eine Wende zum Guten: „Dans le livre de l'histoire du monde une page a été tournée, la page de l'après-guerre. Une page est placée vierge devant la plume des hommes d'Etat, et tous les peuples [...] attendent d'eux que le premier et le dernier mot de cette page s'appelle ,Paix““"

An eine derart segensreiche Fügung glaubten nach München keineswegs alle Franzosen. In die ungeheuere Erleichterung darüber, daß es gelungen war, den Frieden zu retten, mischten sich Scham ob der moralisch verwerflichen Preisgabe der verbündeten Tschechoslowakei ${ }^{4}$ und ein würgendes Gefühl diplomatisch-militärischer Ohnmacht. Das System der kollektiven Sicherheit hatte erneut versagt, in Mitteleuropa vollzog sich ein dramatischer Wandel der Kräfteverhältnisse. „Frankreichs außenpolitische Konzeption, wie sie seit Versailles und Locarno gegolten hatte, war endgültig eingestürzt. "5 Eine leidenschaftlich geführte Debatte, wie künftig mit dem deutschen Expansionsdrang umzugehen wäre, spaltete die französische Gesellschaft ${ }^{6}$. Auch die Befürworter des Münchener Abkommens einte einzig das grundsätzliche Bestreben, einen Krieg zu verhindern. Doch während manche dachten, das sei nur im,Geist von München', durch größtmögliche

1 Abetz, Das offene Problem, S. $85 \mathrm{ff}$., das Zitat auf S. 89.

2 Leitartikel „Der Durchbruch“, unsig.; DFM, Oktober 1938, S. 410.

3 Abetz, La victoire des vaincus?, ebenda, S. 419.

4 Der damalige Le Temps-Korrespondent in Prag, Hubert Beuve-Méry, schrieb bedrückt: „La France vient de manquer, à la face du monde, à des promesses mille fois répétées [...] Si, demain, des millions de Tchèques retombent en servitude, si le maintien de la paix apparaît plus difficile et plus dangereux encore qu'il n'était hier, la France aura trahi purement et simplement. Et l'échec politique s'aggravera du déshonneur." Zit. bei du Réau, Daladier, S. 234.

5 Bellstedt, "Apaisement" oder Krieg, S. 50.

6 Siehe hierzu die ausführliche Studie von Lacaze, L'opinion publique française et la crise de Munich. 
Konzilianz gegenüber den Diktatoren, zu bewerkstelligen, setzten andere auf Festigkeit.

Die Kluft reichte bis in die Führungsspitzen der Außenpolitik. Daladier, ,Munichois' wider Willen, verstand die Vereinbarung vom 30 . September als taktischen Rückzug und dringend benötigte Atempause, um Frankreich für den fast schon als unvermeidlich erachteten Waffengang mental, wirtschaftlich und militärisch zu rüsten; auf eine dauerhafte Übereinkunft mit Hitler mochte er nicht vertrauen. "Wenn ich drei- oder viertausend Flugzeuge gehabt hätte, dann hätte es München nicht gegeben“, sagte er am 3. Oktober bei einem Essen mit Jean Monnet, Luftfahrtminister Guy La Chambre und US-Botschafter Bullitt? ${ }^{7}$. Außenminister Georges Bonnet, ein entschiedener Appeaser, drängte hingegen auf weitere Verhandlungen und ein umfassendes Arrangement mit dem Reich, überzeugt, daß Frankreich nur noch zu Berliner Bedingungen Sicherheit finden könne. Er wollte das Verhältnis zum östlichen Nachbarn durch Anpassung berechenbar gestalten, es durch intensivere Wirtschaftsbeziehungen entkrampfen und Deutschland eine ökonomische Durchdringung Südosteuropas gestatten, während die Franzosen sich verstärkt auf ihr Kolonialreich besinnen sollten ${ }^{8}$.

Die hier skizzierte Zweigleisigkeit, wobei zunächst Bonnet, von März 1939 an Daladier die Akzente setzte, beeinflußte auch die Entfaltungsmöglichkeiten der nationalsozialistischen Propaganda in Frankreich. Kurzlebiger Höhepunkt des Annäherungskurses war eine Freundschaftserklärung, die Bonnet und Ribbentrop am 6. Dezember 1938 im historischen Uhrensaal des Quai d'Orsay unterzeichneten. Sie ließ all jene, die guten Willens waren, noch einmal hoffen. Beide Regierungen bekundeten in dem Schriftstück ihren Wunsch nach guter Nachbarschaft, erklärten die Grenzen zwischen ihren Ländern für „endgültig“ und trafen eine Konsultationsabsprache?. ,Tout Paris' strömte anläßlich der Paraphierung zu Staatsbanketten und Empfängen; die Monatshefte sahen „eine Entwicklung bestätigt, die sich im Bewußtsein beider Völker schon seit geraumer Zeit vollzogen hat". In den politischen Rahmengesprächen bedauerte Ribbentrop, daß sich das psychologische Klima allen Anstrengungen zum Trotz nicht entscheidend verbessert habe. Er ermunterte zu neuen Besuchsprogrammen, besonders von Front-

7 Zit. bei Jean Monnet, Erinnerungen, S. 151. Das Motiv des Zeitgewinns wird deutlich in einer Denkschrift des Quai d'Orsay für Daladier, „Politique étrangère de la France“, vom 16. 11. 1938; DDF, 2, XII, Nr. 314.

8 Bellstedt, „Apaisement“" oder Krieg, belegt die schon vor ,München“ beginnende Neuorientierung Bonnets, der „Sicherheit gerade mit und bei Deutschland“ dem überkommenen französischen Bündnisgefüge vorzog (S. 124), seinen Kurs im Oktober 1938 auf dem Parteitag der Radikalsozialisten in Marseille behauptete (S. 174) und zur Durchsetzung ein personelles Revirement im Quai d'Orsay anschob (S. 147ff.). Siehe auch du Réau, Frankreich vor dem Krieg, in: Hildebrand u.a. (Hrsg.), 1939 - An der Schwelle zum Weltkrieg, S. 173-195; Crémieux-Brilhac, Les Français de l'an 40, I, S. $32 \mathrm{ff}$. Zum Ansatz des ,repli impérial' Girault, La politique extérieure française de l'après-Munich.

9 Abgedruckt ADAP, D IV, Nr. 369. Knippings Urteil, diese Erklärung sei kein substantieller Verständigungsversuch gewesen, tritt Bellstedt hinsichtlich der Motivation Bonnets entgegen (S. 259f.). Vgl. Franz Knipping, Die deutsch-französische Erklärung vom 6. Dezember 1938, in: Hildebrand/Werner (Hrsg.), Deutschland und Frankreich 1936-1939, S. 551 . 
kämpfern und Jugendlichen, was den Stellenwert unterstreicht, den solche Kontakte in seinem Kalkül nach wie vor besaßen ${ }^{10}$.

Nach der Ermordung des deutschen Botschaftsangehörigen vom Rath durch einen jungen Juden Anfang November wurde die Berliner Delegation hermetisch von der Öffentlichkeit abgeschirmt. Abetz, der Ribbentrop begleitete, blieb indes bei der Abreise aus Paris ein anrührendes Bild haften: „Am Ausgang, ich weiß nicht mehr welchen Vororts, erstreckte sich längs des Bahnkörpers ein mehrstökkiges Fabrikgebäude. Als der deutsche Sonderzug in Sicht kam, füllten sich die Fabrikfenster mit Männern und Frauen in weißen Arbeitsblusen, und die hellen Punkte von hunderten winkender Taschentücher grüßten noch ferne aus dem Grau des Wintermorgens, als der Zug die Bannmeile der französischen Hauptstadt schon hinter sich gelassen hatte. ${ }^{11}$

So unwirklich wie diese Szene erscheint in der Rückschau die Ruhe, die Europa im Winter 1938/39 noch vergönnt war. Die Bekundungen des Versöhnungswillens klangen wohl schon damals vielfach „so seltsam schal wie heute beim Studium der Akten"12. Die Erklärung vom 6. Dezember blieb Episode, ihr taktisch-provisorischer Charakter offenbarte sich allenthalben. Während Daladier und Reynaud die Konsolidierung der französischen Staatsfinanzen und die Aufrüstung vorantrieben, ging es Hitler einmal mehr darum, die Westmächte zu beschwichtigen und die Front am Rhein abzusichern als Korrelat für den geplanten Ausgriff nach Osten. Unter dieser Prämisse bot ihm die Freundschaftserklärung eine vorteilhafte Gelegenheit, zu einem "mittelfristig berechneten Modus vivendi mit Frankreich" zu kommen ${ }^{13}$. Der rapide Verfall vermeintlicher französischer Machtpositionen in der Sudetenkrise, erkennbar am wirkungslos gebliebenen Paktsystem, eröffnete aus deutscher Sicht sogar neue Ansatzpunkte für eine Annäherung, bezeichnenderweise aber nur auf der Basis verschobener Gewichte. Infolge seiner geschwächten Position und der wachsenden Beschränkung auf die Verteidigung landeseigener Interessen werde der Nachbar den Bedürfnissen des Reiches „in Zukunft eher Rechnung zu tragen bereit sein als bisher", prophezeite der Pariser Botschaftsrat Carl Bräuer. „Hier bieten sich für uns Möglichkeiten zum Ausbau unseres Verhältnisses zu Frankreich, die sich nicht nur in wirtschaftlichen, kulturellen und sonstigen Beziehungen auswirken würden, sondern uns für lange Zeit den Rücken im Westen freihalten könnten, ohne daß wir uns nach anderen Seiten zu binden hätten." ${ }^{14}$ Kaum zufällig schlug Botschafter Coulondre in jenen Wochen in Berlin eine Woge der Sympathie entgegen. Sämtliche Persönlichkeiten der Reichshauptstadt, mit denen er sich unterhielt, wünschten nachdrücklich gute bilaterale Beziehungen. An der vordergründigen Ernsthaftigkeit ihrer Aussagen mochte Coulondre nicht zweifeln, über die tieferen Absichten war er sich gleich-

10 Leitartikel „Zum Jahresende“, unsig.; DFM, Dezember 1938, S. 521. Aufzeichnung Léger, „Entretiens de M. Georges Bonnet et de M. von Ribbentrop en présence de M. Léger et du Comte Welczeck“, 7. 12. 1938; MAE, Papiers 1940, Cabinet Bonnet/1.

11 Abetz, Das offene Problem, S. 93.

12 Knipping, Deutsch-französische Erklärung, S. 551.

13 Ebenda, S. 538.

14 Bräuer an Auswärtiges Amt, 10. 10. 1938; PA/AA, R 102840. 
wohl völlig im klaren: Die nationalsozialistische Führung suche das Einvernehmen mit Frankreich „pour se couvrir à l'ouest en prévision d'entreprises dans d'autres directions". Teil eins von Hitlers Programm, die Integration aller Deutschen im Reich, sei verwirklicht - „c'est maintenant l'heure du ,Lebensraum' qui sonne". Verschlüsselt, so der Botschafter, deuteten dies alle seine Gesprächspartner an, wobei stets betont werde, daß es keine Desiderata gegen Frankreich mehr gebe. Hitlers Stoßrichtung schien eindeutig: „Se rendre maittre de l'Europe Centrale en vassalisant la Tchécoslovaquie et la Hongrie, puis créer la Grande-Ukraine sous l'hégémonie allemande" 15.

Die Beunruhigungen über Hitlers nächsten Schlag rückten das Treiben der NSPropaganda zunehmend in den Blickpunkt der französischen Diplomatie und Öffentlichkeit. In besorgten Telegrammen vom 19. und 20. Dezember 1938 bezifferte Botschafter Coulondre das Propaganda-Budget nationalsozialistischer Ministerien und Organisationen auf zig Millionen Reichsmark jährlich ${ }^{16}$. Unmittelbar nach dem 6. Dezember beschuldigten mehrere linksorientierte Pariser Blätter vor allem die Gefolgsleute Ribbentrops der nachrichtendienstlichen Tätigkeit und Bestechung. An erster Stelle wurde hierbei Otto Abetz genannt. Le Droit de Vivre, Organ der "Ligue internationale contre l'antisémitisme“, porträtierte ihn als rechte Hand des Reichsaußenministers und unterstellte ihm, dafür gesorgt zu haben, daß sich ein warmer Geldregen auf eine Anzahl Pariser Redaktionsstuben ergoß ${ }^{17}$. Die Wochenzeitung La Lumière zählte Ribbentrops Stab ob seiner effizienten Aufklärungsarbeit über den Willensbildungsprozeß in der französischen Regierung zu den wichtigsten Architekten des deutschen Triumphes von München ${ }^{18}$.

Kein anderer als Jean Luchaire nahm Abetz daraufhin publizistisch in Schutz. Dramaturgisch geschliffen entschuldigte er sich im Namen seiner Landsleute für die Anwürfe, pries den Freund als seriös ("le caractère le plus droit, le plus probe que je connaisse") und erinnerte an seine Verdienste um die Verständigung seit Sohlbergzeiten: „C'est beaucoup grâce à son action amicale, tenace, inlassable voire dangereuse pour lui en Allemagne à certain époque - que la jeunesse de notre voisine de l'Est grandit depuis plusieurs années avec le sentiment qu'une amitié est nécessaire entre la France et l'Allemagne." Auch Abetz' jetzige Tätigkeit sei redlicher Natur und über jeden Zweifel erhaben ${ }^{19}$. Dafür bürgte Luchaire mit seiner „Ehre und Rechtschaffenheit“, denn wer Abetz' Rolle attackiere, ziele auch gegen ihn persönlich ${ }^{20}$. Mit seinen Elogen diente er wohl wieder einmal mehreren Herren. Ständig knapp bei Kasse, bezog er nicht nur regelmäßig Geld von der Deutschen Botschaft, sondern zu Amtszeiten Bonnets auch monatlich 20000 Francs aus einem Geheimfonds des Quai d'Orsay ${ }^{21}$. Es gibt Hinweise, daß er im infor-

\footnotetext{
15 Coulondre an Bonnet, 15. 12. 1938; MAE, Papiers 1940, Cabinet Bonnet/1.

16 Zit. bei. Duroselle, La décadence, S. 209.

17 Révélations sur les amis de von Ribbentrop, in: Le Droit de Vivre, 10. 12. 1938.

18 Le réseau secret de l'espionnage nazi en France, in: La Lumière, 9. 12. 1938.

19 Jean Luchaire, Un mot personnel, in: Notre Temps, 25. 12. 1938, Sp. 400.

20 Ders., Lettre ouverte an Pierre Brossolette, in: Notre Temps, 8. 1. 1939, Sp. 107.

21 So die unangefochtene Feststellung des Vorsitzenden Richters Ledoux im Prozeß gegen Luchaire; Les procès de collaboration, S. 368.
} 
mellen Beziehungsgeflecht zwischen den Spitzen der deutschen und französischen Außenpolitik zeitweilig ähnlich wie Abetz und Brinon als Medium fungierte, zumindest dahingehende Ambitionen hegte ${ }^{22}$. Der Handlungsbedarf in diesem Fall erscheint evident: Bonnet, die druckfrische Freundschaftserklärung in Händen, war auf weitergehende Vereinbarungen mit dem Reich erpicht; er betrachte das Dezember-Abkommen keineswegs als nichtssagenden Akt, sondern als Basis „für weitere Besprechungen im freundschaftlichen Geiste zur dauernden Besserung der deutsch-französischen Beziehungen“, erläuterte er Botschafter Welczeck ${ }^{23}$. Es konnte dieses Vorhaben gefährden, wenn Ribbentrops Frankreichreferent gänzlich unwidersprochen an den Pranger gestellt wurde.

Mit Hilfe ihrer seit langem aufeinander eingespielten Emissäre tasteten sich die Außenminister in den Monaten nach ,München' ab, in Verfolg der jeweiligen Annäherungsstrategie. Am 24. Oktober berichtete Abetz über eine Unterredung mit Bonnet vom gleichen Tag. Hierbei ging es zunächst um einen gewünschten „Gegenartikel“ Daladiers zu einem geplanten Beitrag Ribbentrops für die DeutschFranzösischen Monatshefte. Daladier zögerte offenbar und wollte sich frühestens nach dem Kongreß der Radikalsozialisten Ende Oktober entscheiden ${ }^{24}$. Bonnet versprach, in dieser Sache persönlich beim Ministerpräsidenten vorstellig zu werden. Dann verbreitete sich Abetz über die „Möglichkeiten einer weitgehenderen Fühlungnahme der beiden Länder auf geistigem Gebiete, vor allem seitens der Jugend", und erklärte Schirachs Bereitschaft, einen ursprünglich im Frühjahr vorgesehenen Vortrag an der Sorbonne über "Goethe und Frankreich“, der wegen der Ereignisse in Österreich hatte ausfallen müssen, nunmehr im Dezember zu halten. Bonnet seinerseits signalisierte ein angebliches Interesse Herriots, des Präsidenten der Abgeordnetenkammer, von Hitler empfangen zu werden, und nannte die Erörterung einer wirtschaftlichen Zusammenarbeit als geeigneten Ansatzpunkt für eine "offizielle deutsch-französische Aussprache"25. Um ein solches Gipfeltreffen, bei dem möglichst ein die Beziehungen stabilisierendes Abkommen unterzeichnet werden sollte, war Bonnet nach der Münchener Konferenz emsig bemüht; es sollte seine Außenpolitik in Frankreich stützen. Ribbentrop zeigte sich aufgeschlossen; es müsse nur der „Anschein vermieden werden, als handle es sich um ein deutsches Angebot an Frankreich"26. Die Vorverhandlungen mündeten schließlich in die deutsch-französische Erklärung vom 6. Dezember.

22 Bei einer Vernehmung nach dem Krieg behauptete Luchaire, Bonnet habe ihn nach der Münchener Konferenz gebeten, mit Abetz Kontakt zu halten, "pour des sondages officieux auprès de M. von Ribbentrop, voire du Chancelier Hitler“. Zit. vom Abgeordneten Charles Serre in der Sitzung der parlamentarischen Untersuchungskommission am 3.3. 1949; AN-Enquête, VI, S. 1531. Bei Bonnets Vorgänger im Amt, Paul-Boncour, hatte sich der geschäftstüchtige Journalist gleich selber als Mittelsmann angedient. Wenige Minuten nach dessen Vereidigung zum Außenminister des zweiten Kabinetts Blum am 13. März 1938 sprach Luchaire vor und erklärte sich bereit, vertrauliche Mitteilungen an die Deutschen über Abetz weiterzuleiten. Paul-Boncour lehnte unter Hinweis auf die offiziellen diplomatischen Kanäle ab. Aussage Boncours vom 16. 3. 1948; AN-Enquête, III, S. 813.

23 Welczeck an Auswärtiges Amt, 24. 1. 1939; ADAP, D IV, Nr. 380.

${ }^{24}$ Keiner der beiden projektierten Aufsätze ist in der Folge in den DFM erschienen.

25 Notiz Abetz' für Welczeck, Paris, 24. 10. 1938; ADAP, D IV, Nr. 342.

26 Ribbentrop an Botschaft Paris, 5. 11. 1938; ebenda, Nr. 346. 
Abetz' Bericht dokumentiert einen von zahlreichen Vorstößen der französischen Diplomatie auf dieses Ziel hin und belegt, daß er mittlerweile routinemäßig in Sondierungen auf höchster Ebene eingeschaltet wurde ${ }^{27}$. Prominenten Kritikern Bonnets fühlte er hierbei ebenfalls auf den Zahn, so Paul Reynaud, den er als „unbestrittenes Haupt der ,anti-munichois“" taxierte ${ }^{28}$, anläßlich eines Mittagessens am 22. Oktober. Der damalige Justizminister ließ anklingen, daß Frankreich das "Gespenst einer deutschen Gefahr" brauche, weil sonst der Bevölkerung Wehrwillen und Opferbereitschaft völlig abhanden kämen. Eine Verständigung sei nicht mit ,mous", "womit er offenbar Flandin meinte", sondern nur mit ,durs", was er „mit einem deutlichen Seitenblick auf sich selbst“ sagte, zu bewerkstelligen. Die öffentliche Meinung Frankreichs werde Männer wie Bonnet schon in Kürze desavouieren und den Gegnern der Münchener Vereinbarung zustimmen $^{29}$. Auch über Gegenströmungen zum Schmusekurs Bonnets war die Reichsregierung mithin im Bilde, was präzise propagandistische Reaktionen erleichterte. Wie ein direkter Konter mutet es an, daß der anonyme Leitartikler der DFM (Abetz?) wenige Tage nach den Einlassungen Reynauds "moralische Abrüstung" postulierte und es für "sehr bedauerlich“ erklärte, wenn der Erneuerungsprozeß im Nachbarland, den das "national denkende Deutschland Frankreich von Herzen wünscht", propagandistisch ,auf der Fiktion einer ,deutschen Gefahr “" fuße, nur „weil angeblich kein anderes wirksames Argument gefunden werden könnte“30.

Umgekehrt versuchte Bonnet, die Haltung der Berliner Führung zu erkunden und zu beeinflussen. Auch er stützte sich ganz offensichtlich nicht allein auf seine Berufsdiplomaten, sondern bevorzugte wiederholt inoffizielle Kanäle, was ihm den Vorwurf eintrug, an Parlament und Öffentlichkeit vorbei Geheimdiplomatie zu betreiben. Ebendies war allen Dementis der Beteiligten zum Trotz wohl der Fall, als Fernand de Brinon am 4. Februar 1939 in Berlin eintraf. Offiziell weilte er in seiner Eigenschaft als CFA-Präsidiumsmitglied bei einem internationalen Reitturnier, an dem eine Abteilung der berühmten Kavallerieschule von Saumur teilnahm. Daß Pferdenarr Brinon während seines fünftägigen Aufenthalts in der Reichshauptstadt unter anderem mit Ribbentrop konferierte, ohne daß Botschafter Coulondre eingeweiht war, löste indes Spekulationen aus. Die Pariser Presse mutmaßte, er habe im Auftrag Bonnets hinter dem Rücken der offiziellen französischen Vertretung verhandelt.

27 Schlicht unwahr die Behauptung Bonnets im Jahre 1951, er habe Abetz seinerzeit gar nicht gekannt; AN-Enquête, IX, S. 2609.

28 Abetz, Das offene Problem, S. 118.

29 Wie Anm. 25. Abetz war in Begleitung de Jouvenels bei Reynaud. Verhörprotokoll Nr. 204/49 der Renseignements Généraux vom 26. 11. 1945, „Déclarations relatives à une entrevue Paul Reynaud-Abetz en 1938“; AN, F 7/15331. Flandin hatte Hitler nach dem Münchener Abkommen ein Glückwunschtelegramm geschickt, worauf ihn die Kommunisten als „Seyss-Inquart Frankreichs“ beschimpften und es zu Austritten aus seiner rechtsgerichteten Partei Alliance démocratique kam, allen voran Reynaud. Vgl. Aufzeichnung der Botschaft Paris, 15. 11. 1938; ADAP, D IV, Nr. 353.

30 „Pour un armistice, total ${ }^{` c}$, in: DFM, November 1938, S. 465-468. 
Tatsächlich hatte die Unterredung „eminent politischen Charakter"31. Den Hintergrund bildete die als bedrohlich empfundene Herausforderung der Pariser Regierung durch italienische Gebietsansprüche auf französischen Mittelmeerbesitz. Am 30. November 1938 war es in der römischen Kammer zu antifranzösischen Kundgebungen und lautstarken Rufen nach Tunis, Djibouti, Korsika, Savoyen und Nizza gekommen ${ }^{32}$, die von der heimischen Presse begierig aufgegriffen wurden. Während die italienische Regierung es unterließ, sich eindeutig von den Vorfällen zu distanzieren, bereiste Daladier demonstrativ Nordafrika und verkündete, Frankreich werde nicht einen Millimeter seines Territoriums abtreten, selbst wenn daraus ein bewaffneter Konflikt entstünde ${ }^{33}$. Ribbentrop, den Part des lachenden Dritten und potentiellen Schlichters auskostend, behandelte das Thema bei seinem Paris-Besuch am 6. Dezember mit herablassender Gleichgültigkeit. Er äußerte aus ethnographischen Gründen Verständnis für die Forderungen hinsichtlich Tunesiens und charakterisierte die deutsche Position zu diesem Komplex als "nicht unmittelbar interessiert", jedoch bestimmt von der „unverrückbaren Grundlage“ der ,Achse‘ Berlin-Rom ${ }^{34}$.

Nun legte Brinon dem Reichsaußenminister "in vorsichtiger Form" nahe, zwischen Frankreich und Italien zu vermitteln. Sein Hinweis, die Beziehungen zu Rom seien derart vergiftet, daß sich Frankreich zu Verhandlungen nicht imstande sehe, kam einer verdeckten Bitte gleich, Berlin möge mäßigend auf Mussolini einwirken. Ribbentrop ging allerdings nicht darauf ein. Er ließ selbstgefällig seine „langjährigen“ Verständigungsofferten Revue passieren, anknüpfend an den gemeinsam mit Brinon 1933 eingefädelten Versuch, ein Treffen Hitler-Daladier zu arrangieren. Eine große Konferenz erscheine ihm zum jetzigen Zeitpunkt zwecklos, ja der allgemeinen Stimmung abträglich, wäre sie doch von vornherein zum Scheitern verdammt, weil Paris und London die deutschen Ansprüche - „Abgrenzung der Interessensphären, vor allem Zurückgabe der Kolonien und ähnliches“ nicht offen anerkennen könnten. Es sei deshalb die „viel bessere Politik, die gegenwärtigen Probleme ausreifen [...] und der natürlichen Entwicklung Zeit zu lassen" 35 .

Die Annahme, daß Brinon im Auftrag Bonnets bei Ribbentrop vorsprach, wird durch Indizien erhärtet, nach denen seine Mission Teil einer umfassenderen Initiative war, das gespannte französisch-italienische Verhältnis aufzulockern. Nur wenige Tage zuvor hatte Paul Baudouin, Direktor der Bank von Indochina und späterer Außenminister der Vichy-Regierung, anläßlich einer Geschäftsreise nach Rom mit Ciano und dem ,Duce' gesprochen und danach Daladier, der ihm Instruktionen auf den Weg gegeben hatte, berichtet ${ }^{36}$. Auch in diesem starke Paral-

31 Bellstedt, „Apaisement“ oder Krieg, S. 164.

32 Vgl. v. Mackensen an Auswärtiges Amt, 1. 12. 1938; ADAP, D IV, Nr. 412. DDF, 2, XIII, Nr. 2.

33 Am 13. Dezember 1938; zit. bei Bellstedt, „Apaisement“ oder Krieg, S. 115.

34 Aufzeichnung des Gesandten Schmidt, o.D.; ADAP, D IV, Nr. 370.

35 Aufzeichnung des Legationsrats Brücklmeier „über ein Gespräch des Herrn R.A.M. mit Graf de Brinon am 6. Februar 1939"; ebenda, Nr. 384.

36 Einzelheiten bei Bellstedt, "Apaisement" oder Krieg, S. 163 f., und du Réau, Daladier, S. $330 \mathrm{ff}$. Baudouin hat den Sachverhalt nach dem Krieg bestätigt; AN-Enquête, VII, 
lelen aufweisenden Fall war der französische Botschafter vor Ort, François-Poncet, vorab nicht informiert worden. Am 6. Februar empfing Ribbentrop nicht nur Brinon, sondern unabhängig davon auch Botschafter Coulondre, der bekräftigte, daß Mussolinis Ambitionen die Kriegsgefahr schürten ${ }^{37}$. Ein Fingerzeig, wie eng Brinon und Abetz kooperierten, könnte schließlich eine Beschwerde Abetz' beim Auswärtigen Amt vom 7. Februar sein. Er beanstandete einen Artikel in der jüngsten Ausgabe der Europäischen Revue, der die italienische Frankreichpolitik mit dem grausamen Spiel der Katze (Rom) mit der Maus (Paris) verglich - eine Darstellung, die geeignet sei, „das französische Empfinden auf das Schärfste zu verletzen und unsere Beziehungen zu deutsch-freundlichen Kreisen in Paris zu gefährden“. Das AA möge für eine taktvollere Unterstützung der italienischen Forderungen sorgen und die Europäische Revue anweisen, „die Katze nicht derartig aus dem Sack zu lassen“, wie er, die bildhafte Sprache aufgreifend, formulierte ${ }^{38}$.

Zurück in Paris, sah sich der als notorischer Hitler-Bewunderer verschriene Brinon herben Attacken ausgesetzt. „Comment tolère-t-on ici cet agent allemand? C'est un scandale", echauffierte sich Senator de Leusse im Ratssaal des Hohen Hauses $^{39}$. Henri de Kerillis, der auch in L'Epoque kräftig vom Leder zog, schrieb Brinon, er betrachte es als Gefahr für die Allgemeinheit, wenn eine Person ohne klares Mandat sich erdreiste, zwischen den Regierenden zu pendeln, nach Berlin zu fahren und dort Erklärungen zur französischen Politik abzugeben ${ }^{40}$. Erst Ende Dezember hatte Brinon, durch die permanenten Angriffe seines journalistischen Intimfeindes entnervt, de Kerillis nach alter Väter Sitte zum Duell gefordert und Sekundanten benannt. Kerillis, der in Duellforderungen „les rites démodés, grotesques et publicitaires" sah, verweigerte die Satisfaktion ${ }^{41}$.

Georges Bonnet, schon des öfteren undurchsichtiger Manöver und mangelnder Information der Öffentlichkeit geziehen, stand ebenfalls im Kreuzfeuer der Kritik. Ein erlauchter Zirkel von Wissenschaftlern, Künstlern und Literaten, unter ihnen mehrere Nobelpreisträger, verlangte gar die Einsetzung einer parlamentarischen Untersuchungskommission, die seine Amtsgeschäfte durchleuchten sollte ${ }^{42}$. So vehement der Außenminister und Brinon auch bestritten, daß in Berlin irgendwelche verdeckten Verhandlungen geführt oder angebahnt worden seien ${ }^{43}$,

S. 2058 (Aussage vom 12. 7. 1949). Duroselle, La décadence, S. 513, verknüpft auch die Berlin-Reise Brinons mit dem Namen Daladier.

37 Aufzeichnung Schmidt, 6. 2. 1939; ADAP, D IV, Nr. 382.

38 Abetz an die Presseabteilung des Auswärtigen Amtes, 7. 2. 1939; ebenda, Nr. 385. Vgl. Frhr. v. Freytag-Loringhoven, Politik und Recht: Die französisch-italienische Spannung, in: Europäische Revue, XV. Jg., Februar 1939, S. $109 \mathrm{ff}$.

39 Aux Ecoutes, 26. 2. 1939.

40 Kerillis an Brinon, 2. 3. 1939, nach einem Beschwerdebrief Brinons vom Vortag; AN, 411 AP 1, dr. 6. Vgl. L'Epoque vom 17. 2. und 25. 3. 1939.

41 Lebenslauf „Biographie de Fernand de Brinon“; AN, 411 AP 7, dr. 3. Kerillis an Pierre Benoît (Sekundant), 24. 12. 1938; 411 AP 1, dr. 6.

42 Schreiben der „L'Union des intellectuels français pour la justice, la liberté et la paix“ an den Staatspräsidenten, die Vorsitzenden von Senat und Abgeordnetenkammer sowie Ministerpräsident Daladier vom 11. 3. 1939; MAE, Papiers 1940, Cabinet Bonnet/1.

43 L'Epoque, 17. 2. 1939; Bellstedt, "Apaisement" oder Krieg, S. 165 f.; AN-Enquête, IX, S. 2606f. Vor dem parlamentarischen Untersuchungsausschuß beschrieb Bonnet 1951 
massive Zweifel an ihren Einlassungen scheinen erlaubt. Mißtrauen weckte nicht zuletzt der große Bahnhof, der Brinon bei seinen Deutschlandvisiten regelmäßig bereitet wurde ${ }^{44}$. Den Anhängern einer deutsch-französischen Verständigung blies ein immer rauherer Wind ins Gesicht, wie auch Otto Abetz bald erfahren sollte.

\section{Ende einer Verständigungsphilosophie: Der Zerfall des Comité France-Allemagne}

Die Vernichtung des tschechoslowakischen Reststaates und die Errichtung eines ,Protektorats Böhmen und Mähren' Mitte März 1939 erschütterten endgültig den Glauben der Appeaser, daß Hitlers Ziele begrenzt seien und er großzügige Konzessionen - auf der Basis eines general settlement - mit außenpolitischem Wohlverhalten honorieren würde. Statt dessen unterjochte der Diktator nun erstmals eine nichtdeutsche Bevölkerung, entgegen den bislang proklamierten ethnischen Maximen. Seine Beteuerungen, daß er nur den legitimen Wunsch habe, alle für das Reich optierenden Landsleute in einem Staat zu vereinen, waren damit ebenso hoffnungslos diskreditiert wie die hartnäckigen Verständigungsversuche westlicher Staatsmänner. In deren Lager machte sich Ernüchterung breit, während sich die Hiobsbotschaften häuften: Am 23. März zwangen die Nationalsozialisten Litauen zur Rückgabe des Memelgebiets, ein am gleichen Tag besiegelter Handelsvertrag mit Rumänien erschloß den Zugang zu wehrwirtschaftlich bedeutsamen Ölvorräten. Am 7. April fielen italienische Truppen in Albanien ein. Nächstes Etappenziel deutschen Expansionsdrangs war vordergründig die Freie Stadt Danzig, genau besehen das nunmehr strategisch in die Zange genommene Polen. Mussolini schwebte ein faschistisches ,Mare nostrum“ vor. So reifte in Paris und Lon-

seine Beziehungen zu Brinon als „sehr schlecht“. Er habe mit ihm in dessen Eigenschaft als politischer Journalist verkehrt, darüber hinaus aber jeden persönlichen Kontakt vermieden. Mehrere Schriftstücke im Nachlaß Brinon sprechen eine andere Sprache, etwa ein Gratulationsschreiben Bonnets, als Brinon 1933 zum Offizier der Ehrenlegion ernannt wurde; AN, $411 \mathrm{AP} 1$, dr. 4. In seinen 1949 postum veröffentlichten Memoiren übergeht Brinon die Februar-Reise 1939, in den DFM fand sie ebenfalls keinen Niederschlag.

44 Exemplarisch ein Aufenthalt in Berlin im Januar 1938 auf Einladung Schirachs. Bei seiner Ankunft schritt der Journalist gemeinsam mit dem Reichsjugendführer zu den Klängen der Marseillaise und des Deutschlandliedes eine vor dem Bahnhof Friedrichstraße angetretene Ehrenformation der $\mathrm{HJ}$ ab. Hernach wurde er von Göring, Ribbentrop, dem Präsidium der DFG und Reichsminister Frank empfangen. Eine Unterredung des ausgebildeten Juristen Brinon mit Justizminister Gürtner und dem Direktor der Akademie für deutsches Recht, Lasch, in Anwesenheit des französischen Geschäftsträgers, sollte der „Vertiefung der Beziehungen auf dem Gebiete des Rechts“ dienen. Vgl. Völkischer Beobachter, 21. 1. 1938. Die zurückhaltende Berichterstattung hierüber in der Pariser Presse schrieb der englische Daily Telegraph (22. Januar) dem Umstand zu, daß Brinon als Vertrauter Daladiers anzusehen sei, "the strong man of the new French Government" (Daladier war seinerzeit Verteidigungs- und Kriegsminister). Die kommunistische L'Humanité (22. Januar) hingegen fand es höchst bedenklich, wie Brinon sich gleichsam als Sprachrohr ministerieller Kreise geriere. 
don die späte Einsicht, daß mit den ,Achsenmächten' auf Dauer nicht gütlich auszukommen sei ${ }^{45}$.

Der nationalsozialistische ,Griff nach Prag' am 15. März 1939 markiert einen entscheidenden Wendepunkt in der Vorgeschichte des Zweiten Weltkriegs. Einmal mehr demonstrierte das Hitler-Regime, daß es weder durch Verträge noch Konzessionen zu bändigen, geschweige denn zu saturieren war. Chamberlain und Daladier, ein halbes Jahr zuvor in München bereit, den Frieden um den Preis der Verleugnung eines Verbündeten zu retten, zeigten jetzt, auch unter dem Druck einer empörten Öffentlichkeit, zumindest verbal ihre Entschlossenheit, weitere Schläge nicht mehr hinzunehmen. Bei einem Auftritt in Birmingham am 17. März zählte der britische Premierminister Hitlers Wort- und Vertragsbrüche auf und kündigte energischen Widerstand gegen eine fortgesetzte deutsche Expansion an: „any attempt to dominate the world by force was one which the Democracies must resist" ${ }^{46}$. Amtskollege Daladier bekräftigte ebenfalls, daß das Maß voll sei. Frankreich werde sich künftig "mit einmütiger Kraftanstrengung zur Verteidigung der Freiheit erheben“ und ,jeder durch Gewalt oder durch die Drohung mit Gewalt erzwungenen Änderung des Status quo [...] entgegentreten ${ }^{\text {" }}{ }^{7}$. Der Wille zu mehr Festigkeit manifestierte sich in britisch-französischen Garantien für Polen (31. März), Griechenland und Rumänien (13. April) sowie halbherzig geführten Bündnisverhandlungen mit der Sowjetunion.

Auch in der französischen Öffentlichkeit war ein spürbarer Umschwung zu verzeichnen. Weite Bevölkerungskreise schienen trotz tiefempfundener Friedensliebe nicht länger gewillt, ein Arrangement mit Deutschland und Italien um jeden Preis zu akzeptieren. Botschafter Welczeck konstatierte einen „Zustand der Gereiztheit [...], der seinen Ausdruck findet in den häufig zu hörenden Worten ,ça ne peut pas continuer ainsi'“. 48 Daladier, autoritär und volkstümlich zugleich, gestärkt nicht zuletzt durch die erfolgreiche Wirtschaftspolitik seiner Regierung, genoß größere Popularität denn $\mathrm{je}^{49}$. Unter dem Druck der äußeren Ereignisse verloren innenpolitische Gegensätze an Schärfe, präsentierte sich die Nation so geschlossen wie seit langem nicht ${ }^{50}$. Friedrich Grimm, wie häufig am Puls des Geschehens, kommentierte trocken: „München ist tot [...] Wir haben keinerlei Rückendeckung mehr in Frankreich, jedenfalls im Augenblick." Der Bruch im massenpsychologischen Gefüge dünkte ihn „vielleicht tiefgehender als jemals zuvor" "51. Doktrinäre Pazifisten der nichtkommunistischen Linken und Ultrarechte gerierten sich - aus unterschiedlichen Motiven - zwar weiterhin als ,Muni-

45 Ein konziser Abriß zur Appeasementpolitik und ihrem Fehlschlagen bei Adamthwaite, Making of the Second World War, Kap. 5 und 6.

46 Zit. bei Taylor, Origins of the Second World War, S. 253.

47 Radioansprache am 29. 3. 1939, Regierungserklärung vom 13. April; zit. bei Jean-Pierre Azéma, Die französische Politik am Vorabend des Krieges, in: Benz/Graml (Hrsg.), Sommer 1939, S. $284 \mathrm{f}$.

48 Welczeck an Auswärtiges Amt, 13. 5. 1939; ADAP, D VI, Nr. 379.

49 Vgl. Heimsoeth, Dritte Republik, S. 33 ff.; du Réau, Daladier, 3. Teil, Kap. V.

50 Bericht Bräuers vom 19. 4. 1939; PA/AA, R 102859.

51 „Bericht über Pariser Reise vom 12.-18. März 1939“, in: Grimm, Frankreich-Berichte, S. 132-137, die Zitate S. 134. 
chois', doch im nun vorherrschenden Meinungsklima blieb der Einfluß selbst so pointierter Stellungnahmen wie der von Marcel Déat begrenzt. „Flanquer la guerre en Europe à cause de Dantzig, c'est y aller un peu trop fort", hatte Déat erklärt, „les paysans français n'ont aucune envie de mourir pour les Poldèves. “52

Zwar blieb das Bedürfnis nach Frieden bestimmendes Moment in der öffentlichen Diskussion, doch erschien der Preis vielen allmählich zu hoch. Selbst ein exponierter ,Munichois' wie Jean Luchaire wurde nachdenklich. Noch Anfang März hatte er Bonnet vorbehaltlos verteidigt und für eine in Gourdon gehaltene Rede gelobt. Der Außenminister hatte unter Hinweis auf entsprechende Äußerungen Ribbentrops seine Zuversicht bekräftigt, daß die deutsch-französische Erklärung vom 6. Dezember die erste Etappe auf dem Weg zu vertrauensvollen Beziehungen sei. Notre Temps stellte sein Wirken - „dans l'esprit comme dans la pratique" - in eine direkte Kontinuitätslinie zu Aristide Briand, nicht ohne zu betonen, daß die Zeitung stets das gleiche hehre Ziel verfolgt habe ${ }^{53}$. In der nächsten Ausgabe legte das Blatt nach: Man müsse, wie Bonnet es praktiziere und Briand es getan hätte, den Frieden mit den vorhandenen Mitteln und letztem Einsatz bewahren ${ }^{54}$. Wiederum eine Woche später räumte Luchaire ein, daß Hitlers Beteuerungen als Trug entlarvt seien. Mit dem Einmarsch in Prag habe der ,Führer' unstrittig die "völkische Plattform" verlassen und die seitherige ideologische Rechtfertigung seiner Gebietsansprüche ad absurdum geführt ${ }^{55}$. Ungewohnt scharf reagierte Luchaire auf den Leitartikel in der April-Ausgabe der $D F M$, der die jüngste deutsche Expansion mit geopolitischen Argumenten zu bemänteln suchte. Wer die Staatsräson über die Gerechtigkeit erhebe, das geographische über das ethnische Prinzip, die Theorie des ,Lebensraums' über Freiheit und Unabhängigkeit, betreibe "klassischen Imperialismus". Dieser aber, warnte Luchaire, habe noch stets im letzten siegreiche Koalitionen gegen sich vereint ${ }^{56}$.

Besonders anschaulich läßt sich der Gezeitenwechsel bei den Frontkämpferverbänden dokumentieren, die so geduldig einem Ausgleich das Wort geredet hatten. Nun verlangten sie entschieden die Eindämmung nationalsozialistischer Expansionsgelüste. UNC-Präsident Jean Goy rief unter dem Beifall von 50000 Zuhörern in Arcachon: „Les promenades militaires, les conquêtes sans risque, c'est maintenant fini; la France crie: Halte-là! ${ }^{57}$ Henri Pichot, der nach der als Demütigung

52 Déat, Mourir pour Dantzig?, in: L'CEuvre, 4. 5. 1939. Neuere Untersuchungen stimmen darin überein, daß der Artikel hauptsächlich entschiedenen Widerspruch erntete. Siehe Azéma, La France de Daladier, in: ders./Bédarida (Hrsg.), La France des années noires, 1, S. 35; Burrin, La dérive fasciste, S. 273; Brender, Kollaboration in Frankreich, S. $66 \mathrm{ff}$. Schramm nannte ihn einst ,ein psychologisches Geschenk [...], das gut und gern ein Panzerkorps wert war"; ders., Hitlers psychologischer Angriff, S. 56.

53 Luchaire, De Gourdon à Gourdon, in: Notre Temps, 5. 3. 1939, Sp. $817 \mathrm{ff}$.

54 Georges Suarez, De Briand à G. Bonnet, in: Notre Temps, 12. 3. 1939, Sp. $867 \mathrm{f}$.

55 Luchaire, Le III Reich à Prague, in: Notre Temps, 19. 3. 1939, Sp. 915. Dort auch die aus heutiger Perspektive weitsichtige Vorhersage: „L'histoire dira peut-être un jour que la date du 15 mars 1939 aura été plus fatale au Troisième Reich qu'à la Tchécoslovaquie ellemême."

56 Luchaire, Persévérer? Mais comment?, in: Notre Temps, 16. 4. 1939, Sp. $1057 \mathrm{ff}$. Vgl. DFM, April 1939, S. 193-200 (Leitartikel „Blut und Boden“, unsig.).

57 Zit. bei Crémieux-Brilhac, La France devant l'Allemagne et la guerre au début de septem- 
Frankreichs empfundenen Münchener Konferenz eindringlich zu nationaler Geschlossenheit aufrief, erklärte ebenso unmißverständlich: „Il ne s'agit plus de discuter avec Hitler. Il s'agit d'opposer nos actes à ses actes et de faire que notre force barre sa force. Le reste, littérature. " ${ }^{8}$ Ende April geißelte er vor Veteranen in Colmar den "gefährlichen und maßlosen Ehrgeiz" der Diktatoren, die Europa im Namen des ,Lebensraums' zu knechten versuchten. Doch die Welt sei „erwacht“ und sammele sich. Auch das friedliebende französische Volk sehe sich angesichts der von Deutschland und Italien ausgehenden Kriegs- und Dominationsgefahr gezwungen, „Gewalt mit Gewalt zu beantworten“. Die Rettung des Friedens liege im Zusammenschluß der freien Völker zur Verteidigung von Menschenrecht und Zivilisation. „Europa will sich nicht in ein Konzentrationslager verwandeln lassen“59.

In einem privaten Gespräch hatten die beiden Generalsekretäre des CFA bereits Ende Dezember 1938 eine traurige Bilanz gezogen: Jahre wechselseitiger Besuche und rege kulturelle Austauschbeziehungen hatten die politische Entwicklung nicht entscheidend beeinflußt. Die Mitglieder der Deutsch-Französischen Gesellschaft seien aufrichtig, insistierte Goy; doch wenn sie nicht erkennen wollten, daß sie nur die Galerie belustigten, während ihr ,Führer ' den Völkern ins Fleisch schneide, dann sei das kein Grund für die französische Schwestergesellschaft, sich ebenfalls an der Nase herumführen zu lassen. Es gebe zudem unbestreitbar Mißstimmigkeiten in der Auslegung der Menschenrechte, ergänzte Pichot. Man dürfe nicht länger schweigen und so den Eindruck erwecken, als billige man die inneren Zustände im NS-Staat ${ }^{60}$. Dieselben Männer, die es über Jahre hinweg als patriotische Pflicht erachteten, Versöhnungsarbeit an der Basis zu leisten, die ebenso naiv wie von Friedensliebe beseelt an Hitlers Wohlverhalten hatten glauben wollen, steigerten sich nun, restlos desillusioniert, in eine regelrechte Kreuzzugstimmung wider den braunen Terror hinein.

Das Comité France-Allemagne, von den Frontkämpfern maßgeblich inspirierter Hort der Verständigungsphilosophie, geriet zwangsläufig unter Druck und brach auseinander. Prominente Mitglieder verweigerten ihre Unterstützung, schieden im Groll. „Am bittersten sprechen sich gerade unsere Freunde aus“, notierte Grimm. Selbst wohlmeinende Persönlichkeiten wie Brinon beklagten sich, daß sie „keinerlei Informationen" hätten und keine stichhaltigen Argumente, um das deutsche Vorgehen vor der französischen Öffentlichkeit zu begründen. „Sie müssen sich heute entschuldigen. Sie ziehen sich darauf zurück, daß sie guten

bre 1939, in: Hildebrand/Werner (Hrsg.), Deutschland und Frankreich 1936-1939, S. 604 f.; ders., Les Français de l'an 40, I, S. 63 ff.

58 Pichot, Voir clair, in: L'Çuvre, 25. 3. 1939.

59 Ansprache vor der Union des invalides et anciens combattants d'Alsace et de Lorraine, 30. 4. 1939; Redemanuskript im Nachl. Pichot, AN, 43 AS 2, dr. 1.

60 Pichot, Et ce fut quand même la guerre, pag. 87. Die letzte Bemerkung spielt auf die ,Kristallnacht' an. Nach dem Judenpogrom wies Pichot die Behauptung, der Volkszorn habe sich spontan entladen, als nationalsozialistische Propagandalüge zurück: „il n'en peut pas être ainsi dans un pays où tout est ordonné, où rien se passe sans permission “. Ders., Pour être lu à Berlin, in: L'CEuvre, 16. 11. 1938. 
Glaubens gewesen [...]; daß sie getäuscht worden seien."61 Schon im Herbst 1938 war es zu ersten Austritten aus dem CFA gekommen. In den Augen Bertrand de Jouvenels und anderer machte bereits ,München' alle Hoffnung auf eine dauerhafte Einigung mit Hitler-Deutschland zunichte. Jouvenel diente sich deshalb sogar der militärischen Abwehr als Informant an. Auf Vermittlung von Abetz bereiste er im November/Dezember 1938 in seiner Eigenschaft als Journalist Deutschland, besichtigte Hochöfen, Siemens und die Junkers-Werke, wo ihm in unverkennbarer Einschüchterungsabsicht Einblicke in die Rüstungsanstrengungen und die umfassende Mobilisierung der Werktätigen ermöglicht wurden. Bestürzt registrierte er, daß der Respekt vor Frankreich und seiner Armee nicht mehr sonderlich groß sei62.

Noch vor den Prager Ereignissen legte Georges Scapini den CFA-Vorsitz nieder. Ein Nachfolger wurde nicht mehr gewählt. Statt dessen erschien in der Pariser Tagespresse am 24./25. März 1939 folgende Notiz: „Le comité directeur, réuni le mercredi, 22 mars, considérant les récents événements en Europe centrale, a décidé, à l'unanimité, de suspendre son activité et de convoquer une assemblée générale afin d'envisager une dissolution éventuelle du Comité France-Allemagne.“63 Ein Teilnehmer der Sitzung erklärte hierzu vor Reportern, man habe nach besten Kräften für die Verständigung gearbeitet, glaube weiter, daß das deutsche Volk in Frieden leben wolle, könne aber nicht umhin festzustellen, daß Hitlers Politik Europa an den Rand einer Katastrophe geführt habe ${ }^{64}$.

Die am 22. März im Präsidium getroffene Entscheidung, die Aktivitäten des Komitees zumindest bis zur Einberufung einer Generalversammlung ruhen zu lassen, fiel keineswegs einstimmig. Goy und Pichot hatten sogar eine unverzügliche Auflösung der Organisation beantragt ${ }^{65}$ und offenbar etliche Vorstandsmitglieder auf ihrer Seite. Nur mit Mühe gelang es Brinon, Ernest Fourneau und dem Comte de Chappedelaine, „einen übereilten Beschluß zu vermeiden“, wie Botschaftsrat Bräuer nach Berlin meldete. Der jetzt vereinbarte Modus sei das mindeste gewesen, was den Verfechtern einer sofortigen Liquidation zu konzedieren war. Brinons Fraktion spiele nun auf Zeitgewinn und hoffe auf ruhigeres Fahrwasser für die Vollversammlung. Nach Bräuers Informationen hatte das CFAPräsidium die Deutsch-Französische Gesellschaft umgehend über seine Beschlüsse in Kenntnis gesetzt, ebenso - „wie üblich“ - die "zuständigen Herren“

61 Grimm, Frankreich-Berichte, S. 134, 136.

62 Jouvenel, Voyageur, S. 338 ff.; ders., Nach der Niederlage, S. 105 f. Vgl. Sick, Vom Neoliberalismus zum Faschismus?, S. $69 \mathrm{f}$. Den Generalstabschef der französischen Luftwaffe, Vuillemin, schauderte nach einem Deutschlandbesuch im August 1938 vor den materiellen Ressourcen und der Moral der deutschen Verbände. Seine Gastgeber hätten keine Gelegenheit ausgelassen, ihre militärische Schlagkraft zu demonstrieren. In charakteristischem Kontrast hierzu unterstrich Hitler bei einem Empfang seine Sympathien für Frankreich und die Frontkämpferverständigung. Aufzeichnung Vuillemins vom 23. 8. 1938 über Gespräche mit Hitler und Göring am 18. August, zusammenfassender Bericht des Generals über seine Mission vom 2. September; MAE, Papiers 1940, Cabinet Bonnet/1.

63 Zit. nach Cahiers de l'Union fédérale, Nr. 163, 25. 3. 1939. Höhnischer Kommentar Kerillis': „M. von Brinontrop perd son emploi.“ L'Epoque, 25. März.

64 Le Journal, 24. 3. 1939.

65 Cahiers de l'Union fédérale, Nr. 163. 
der Dienststelle Ribbentrop ${ }^{66}$. Fast beiläufig bestätigt diese Formulierung, daß die „Dienststelle` via DFG routinemäßig auf deren Pariser Pendant Einfluß zu nehmen pflegte.

Otto Abetz eilte nach Paris, um den Zerfallsprozeß aufzuhalten. Er versuchte Pichot umzustimmen, bot seine ganze Überzeugungskraft auf, plädierte leidenschaftlich für den Fortbestand des Comités - vergebens ${ }^{67}$. Der Generalsekretär anerkannte den guten Willen der DFG, betonte indes, daß man sich über den kulturellen Austausch hinaus der Verbesserung der politischen Beziehungen verpflichtet fühle und diesbezüglich gescheitert sei. Gegenwärtig, da ausschließlich die Politik bestimme, sei kein Platz mehr für „Spiele“. Seine Kameraden und er stünden loyal hinter ihrer Regierung, alles andere wäre unwürdig. Abetz schien „erschüttert, aufgewühlt, betrübt" 68 zu sein, Pichot erstaunlicherweise nach wie vor überzeugt von der persönlichen Integrität des Deutschen. Noch 1944, im Rückblick auf die dreißiger Jahre, fühlte er mit ihm: ,Je sais tout ce qu'il a fait [...] pour la naissance d'un, esprit franco-allemand'. Je sais que c'est là sa raison d'agir la plus intime et la plus sincère [...] Il m'a fait plus d'une confiance. Sa francophilie avouée et militante lui a valu des soupçons, des accusations, des menaces. Il a parfois joué sa situation, sinon sa sécurité personnelle."

Die mit Spannung erwartete Generalversammlung des CFA am 24. Mai besiegelte das Ende der Gesellschaft, wenngleich die laut Satzung für eine Auflösung erforderliche Zweidrittelmehrheit nicht zustande kam. Es war ein Abgesang voller Mißklänge. Nach erregten Debatten, Radau, tumultartigen Szenen und einer wahren Abstimmungsschlacht schieden die Anwesenden im Unfrieden. Einige jüngere Mitglieder sollen durch englandfeindliche Parolen aufgefallen sein. Senator Henry-Haye, der Abgeordnete Pierre Béranger und Professor Fourneau machten sich für den Fortbestand des Comités stark, während Jean Goy - „in einer recht hetzerischen Rede", wie Botschafter Welczeck erfuhr - und Henri Pichot - „in gemäßigter Form“ - als Wortführer der Auflösungsbefürworter hervortraten und den Austritt ihrer Verbände aus dem CFA bekanntgaben ${ }^{69}$. Nicht zum ersten Mal habe eine Minderheit ihren politischen Passionen schamlos freien Lauf gelassen, dem auf Ausgleich bedachten Geist der Gründerväter zuwider, kommentierte die Verbandszeitung der Union fédérale ${ }^{70}$. Über das genaue $\mathrm{Ab}-$ stimmungsergebnis herrschte heillose Verwirrung. Die Nachrichtenagentur Havas meldete 173:124 Stimmen zugunsten einer Auflösung des Comités, L'Epoque ein Votum von 132:125. Die Unsicherheit resultierte nach Darstellung Welczecks aus der hitzig diskutierten Frage, ob Goy und Pichot im Namen der Anciens combattants jeweils 40 Kollektivstimmen abgeben dürften. Versammlungsleiter Scapini erlaubte dies schließlich mit dem vielsagenden Hinweis, daß

66 Bräuer an Auswärtiges Amt, 26. 3. 1939; PA/AA, Botschaft Paris 1297.

67 Das Folgende nach Pichot, Et ce fut, S. $92 \mathrm{f}$.

68 "Emu, troublé, peiné

69 Welczeck an Auswärtiges Amt, 27. 5. 1939; PA/AA, Botschaft Paris 1297. Vgl. Pichot, Et ce fut, S. 93 f., und L'Epoque vom 27. Mai („La tumultueuse agonie de l'Association France-Allemagne ${ }^{\alpha}$ ).

70 Cahiers de L'Union fédérale, Nr. 167, 25. 5. 1939. 
man auch in der Vergangenheit die Sonderstellung der Präsidenten der Frontkämpferverbände respektiert habe. Kaum aber waren die Stimmzettel eingesammelt, soll Pichot mit Rücksicht auf die geharnischten Proteste doch auf seine 40 Stimmen verzichtet haben, was dann zu Rechenfehlern und unterschiedlichen Auszählungsresultaten führte ${ }^{71}$.

Das Comité France-Allemagne, wiewohl faktisch erst bei Kriegsbeginn aufgelöst, stellte nach diesem skandalträchtigen Abend alle Aktivitäten ein. Die karge Acht-Zeilen-Meldung der $D F M$, die Versammlung habe sich für eine „Weiterführung" entschieden, entsprach nicht den Tatsachen und verdrehte den Umstand, daß die erwähnte $Z$ weidrittelmehrheit nicht erzielt wurde, auf unseriöse Weise zu propagandistischen Zwecken ${ }^{72}$. Vizepräsident Brinon, zunächst zum Weitermachen bereit, zog sich auf sein Landgut Orriule nahe der spanischen Grenze zurück, schmollend und der ständigen Anschuldigungen überdrüssig, ein verkappter Nazi-Agent zu sein ${ }^{73}$. Damit entfielen wichtige Anlaufstellen, Informanten und Meinungsmultiplikatoren für Abetz. Seine propagandistische Tätigkeit in Frankreich wurde im Frühjahr 1939 außerdem durch mehrere regierungsamtliche Dekrete zur inneren Sicherheit und eine zunehmend kritische Berichterstattung der Presse im Gefolge der wachsenden internationalen Spannungen weiter erschwert ${ }^{74}$. Die Zeiten, da ihm die Sympathien leichtgläubiger Franzosen zuflogen, waren passé. Statt dessen sah er sich nun vielerorts mit massiven Vorbehalten und bohrenden Fragen konfrontiert, so im März bei einem vom CFA organisierten Vortrag in Lyon. Abetz sollte vor Studenten über ,soziale Errungenschaften im Dritten Reich" referieren. Die Diskussion drehte sich aber rasch um den Einmarsch der Wehrmacht in Prag, und er hatte, wie er Jahre später vor Gericht sagte, Schwierigkeiten, sich zu verteidigen ${ }^{75}$.

71 Welczeck an Auswärtiges Amt, wie Anm. 69.

72 DFM, Juni 1939, S. 422. Die gleiche Falschmeldung im August/September-Heft, S. 508.

73 „Biographie de Fernand de Brinon“; AN, 411 AP 7, dr. 3. Les procès de collaboration, S. 14.

74 An erster Stelle ist hier das „Décret tendant à réprimer les propagandes étrangères“ zu nennen, am 21. April von Staatspräsident Lebrun unterzeichnet und laut Anschreiben Daladiers "une nécessité de défense nationale“. Es richtete sich besonders gegen die Bestechung und propagandistische Vereinnahmung von Franzosen durch Fremdmächte. Mit Gefängnis bis zu fünf Jahren mußte rechnen, wer in Diensten bzw. im Sold ausländischer Propagandastellen stand. Der Erhalt ausländischer Geldmittel für kommerzielle Werbezwecke war fortan meldepflichtig (J.O., Lois et décrets, 25. 4. 1939, S. 5296). Ein Dekret vom 6. Mai erleichterte es dem Innenminister, ausländische Druckerzeugnisse zu verbieten; aufgrund dieser Handhabe wurden im August die Deutsch-Französischen Monatshefte aus dem Verkehr gezogen. Weitere Dekrete untersagten die unautorisierte Weitergabe militärischer Informationen (20. März), verschärften die Sanktionen bei Verunglimpfung bestimmter ethnischer und religiöser Bevölkerungsgruppen (21. April) und stellten die Verbreitung von Flugschriften, Handzetteln und ähnlichen Publikationen, die ausländischer Herkunft oder von Fremdmächten inspiriert waren und die nationale Sicherheit gefährdeten, unter Strafe (24. Juni). Vgl. Fernand Terrou, L'Evolution du droit de la presse de 1881 à 1940, in: Bellanger u.a. (Hrsg.), Histoire générale de la presse française, III, S. $51 \mathrm{f}$.

75 Abetz-Prozeß, 12. 7. 1949, pag. 23 ff.; AN, 334 AP 49. Die Behauptung eines Lyoneser Offiziers, wonach Abetz vor befreundeten Franzosen in einem Lokal erklärt haben soll, 


\section{Abgründe einer fixen Idee: Frieden mit Frankreich auf Kosten Polens}

Die Unterwerfung der Tschechoslowakei stürzte Abetz nach eigener Darstellung in ein Dilemma. „Waren mir alle bisherigen außenpolitischen Initiativen der deutschen Regierung, trotz ihrer manchmal anfechtbaren Form, innerlich berechtigt erschienen, so befand ich mich gegenüber dieser neuen Aktion in der peinlichen Lage, daß ich sie auch in der Sache nicht gutheißen konnte", schreibt er in seinen Memoiren ${ }^{76}$. Doch schon zwei Absätze weiter ist er wieder ganz nationalsozialistischen Denkkategorien verhaftet und riskiert einen gewagten Vergleich: „Die ,tschechische Bastion' nahm unbestreitbar im deutschen Staats- und Volksraum den gleichen beherrschenden Platz ein wie etwa das Massif Central in Frankreich, sie konnte im Kriegsfall einer feindlichen Koalition als Waffenlager und Flugbasis dienen. Gleich welcher Nationalstaat hätte ein derartig gelegenes Gebiet im Laufe seiner Geschichte schon längst politisch und kulturell mit sich verschmolzen."77 Auch im Spiegel zeitgenössischer Dokumente ist ein qualvoller Gewissenskonflikt nicht zu erkennen, geschweige denn eine Distanzierung von den Geschehnissen. Vielmehr erscheint Abetz wieder einmal als loyaler Interpret der Berliner Machthaber. Unter seiner maßgeblichen Mitwirkung führten die Deutsch-Französischen Monatshefte erneut eine massive Kampagne zur Rechtfertigung der nationalsozialistischen Außenpolitik ${ }^{78}$.

Völkische Argumente, die bei früheren Annexionen in deutschfreundlichen Kreisen im Ausland durchaus verfangen hatten, stachen nicht mehr - das Reich hatte das vielbemühte Prinzip der Selbstbestimmung und der ethnischen Revision der in Versailles gezogenen Grenzen zu eindeutig verletzt und in den Augen der Weltöffentlichkeit nackten Imperialismus praktiziert. So wurden nun im Fall Böhmen/Mähren kurzerhand die historischen und geographischen Gegebenheiten für „derartig zwingend“ erklärt, daß diesesmal das eigentlich viel erstrebenswertere „reine Rasseprinzip“ habe hintanstehen müssen. Im Gleichklang mit anderen NS-Organen wurden die Einwände des Auslands mittels schlichter Arithmetik als wunderlich abqualifiziert: „Als im Staate des Professors Benesch sieben Millionen Tschechen dreieinhalb Millionen Sudetendeutsche politisch bevormundeten, fanden Herr Benesch und mit ihm fast die ganze Welt dieses in Ordnung [...] Wenn heute in einem föderalistischen Staatsgefüge 80 Millionen Deutsche die politische Führung über sieben Millionen Tschechen übernehmen, nimmt die Welt hieran Ärgernis." Dabei werde den Tschechen eine nachgerade beispielhafte administrative und kulturelle Autonomie zugestanden ${ }^{79}$. Im Mai-Heft der DFM

linksrheinische Gebiete germanischen Ursprungs müßten wieder ins Reich eingegliedert werden, wies der Angeklagte als Erfindung zurück.

76 Abetz, Das offene Problem, S. 95.

77 Ebenda, S. $95 \mathrm{f}$.

78 Einziger Kontrapunkt war der schon erwähnte kritische Beitrag des Lyoneser CFA-Mitglieds Bérard, der freilich auch als Aufhänger für Repliken, mithin propagandistischen Gesichtspunkten, diente.

79 Leitartikel „Blut und Boden“, unsig.; DFM, April 1939, S. 193-200. Die gleichen Begrün- 
entwarf Reichsinnenminister Frick ein höchst vorteilhaftes Tableau von der Lage der ethnischen Minderheiten im Großdeutschen Reich. Er verneinte ihre zwangsweise Germanisierung und beteuerte, Staat und Partei achteten, ja garantierten die natürlichen Lebensrechte dieser Bevölkerungsgruppen [sic!]. Böhmen und Mähren beanspruchte er als einen von alters her traditionell "deutschen Lebensraum " 80 . In der Juni-Ausgabe der Revue legte Abetz persönlich nach, die mittlerweile sattsam bekannten Argumente wiederholend. Der Ton ist merklich schärfer als in den voraufgegangenen Beiträgen, die primär auf eine Beruhigung der Gemüter in Frankreich zielten. Abetz beschuldigte die Westmächte, sie hätten das Münchener Abkommen nur akzeptiert, um einen Konflikt zu vermeiden, nicht um geschehenes Unrecht gutzumachen. Die Tschechen hätten sich dem Reich gegenüber längst nicht so kooperativ verhalten, wie man das habe erwarten dürfen; auch dies rechtfertige die Wiederherstellung einer „von den geographischen Gesetzen und einer über 1000jährigen Geschichte gewollten Ordnung“. Im übrigen verortete er den ,Griff nach Prag" als notwendigen Schritt zur unumgänglichen Revision des Versailler Vertrages ${ }^{81}$.

Seine Überzeugung, daß das Versailler System obsolet sei, ließ ihn auch für die offiziellen deutschen Forderungen in der Danzig- und Korridorfrage einstehen, die im Frühsommer 1939 wieder aktuell wurden. Doch nicht Danzig, sondern „die Erweiterung des Lebensraumes im Osten“" war eigentliches Objekt nationalsozialistischer Begierde, wie der ,Führer' am 23. Mai vor Wehrmachtgenerälen bekannte. Polen, das sich hartnäckig weigerte, in ein Satellitenverhältnis zum Reich zu treten, sollte „bei erster passender Gelegenheit" liquidiert werden ${ }^{82}$. Im April hatte Hitler den deutsch-polnischen Nichtangriffspakt und das Flottenabkommen mit England aufgekündigt und dem OKW befohlen, den ,Fall Weiß` (Angriff auf Polen) so zu bearbeiten, „daß die Durchführung ab 1.9.1939 jederzeit möglich ist"83. Inwieweit Abetz über diesen hemmungslosen Hang zur Gewalt im Bilde war, entzieht sich unserer Kenntnis. In seinen Erinnerungen verteilt er die Verantwortung für die hereinbrechende Katastrophe, die NS-Führung entlastend, auf viele Schultern, angefangen bei den Siegern des Ersten Weltkriegs, die mit der Abtrennung Danzigs vom Reich und der Errichtung des Korridors eine „Todsünde am Frieden" begangen hätten. Er rügt wahnwitzige italienische Forderungen und „übereilte Schritte“ der Reichsregierung, die bei den Westmächten „Befürchtungen wecken und die Kriegsbereitschaft erhöhen " mußten, ebenso wie die angeblich Oberwasser gewinnende „Kriegspartei“ jener Länder, so daß man die Schuld "nicht ausschließlich Deutschland zuschreiben“ dürfe. Von einer mysteriösen „Aufhetzung Polens gegen Deutschland“ ist die Rede, mit deutlich antibritischer Spitze. Eine insgesamt peinliche Argumentationskette, die sich zwölf Jahre

dungen, zum Teil in fast wörtlicher Übereinstimmung, bei Abetz, Das offene Problem, S. 96. Vgl. Joachim Benecke, Un nouveau Saint-Empire?, in: DFM, April 1939, S. 201-204 („l'espace vital du peuple exige ça et là des corrections pour des raisons géographiques“).

80 Wilhelm Frick, Les minorités ethniques du Reich allemand, in: DFM, Mai 1939, S. 273287.

81 Abetz, Versailles, vingt ans après, in: DFM, Juni 1939, S. 349-355.

82 Protokoll des Wehrmachtadjutanten Oberstleutnant Schmundt; ADAP, D VI, Nr. 433.

${ }^{83}$ Hubatsch (Hrsg.), Hitlers Weisungen für die Kriegführung, Nr. 1a, das Zitat S. 22. 
nach Kriegsausbruch noch immer in streng revisionistischen Bahnen bewegt und zwischen den Zeilen manche Schuldzuweisung an den überfallenen Nachbarn im Osten enthält ${ }^{84}$.

Als sich der Nervenkrieg um Danzig zuspitzte, war Abetz erneut unterwegs, um die öffentliche Meinung in Frankreich im nationalsozialistischen Sinn zu beeinflussen. Er warb um Verständnis für die „durchaus diskutablen“ deutschen Forderungen und bestürmte seine vielen Bekannten, auf eine friedliche Lösung des Konflikts hinzuwirken. Hierbei ist er, wie seine eigenen Einlassungen belegen, wohl ziemlich massiv geworden. Man solle keine Illusionen hegen, schärfte er seinen Gesprächspartnern ein, daß die Westmächte Hitler durch Unnachgiebigkeit in die Knie zwingen könnten. Die Deutschen stünden in der Danzigfrage geschlossen hinter ihrer Regierung, militärische Gegenmaßnahmen seien angesichts der Stärke des Reiches sinnlos und würden „mit blutigen Verlusten für den Angreifer" abgewiesen. Polen selbst wäre im Ernstfall „,in spätestens 15 Tagen militärisch völlig zerschlagen" 85 . Nach amtlicher französischer Lesart hat er „in sensationeller Weise" einen unmittelbar bevorstehenden Handstreich auf Danzig angekündigt und systematisch das Gerücht verbreitet, der Westen würde sich für die Freie Stadt nicht schlagen ${ }^{86}$.

Durch seine Kampagne, deren Schwerpunkt auf Abschreckung lag und mit deren Hilfe die französische Kampfbereitschaft geschwächt werden sollte, machte sich Abetz zum Handlanger für das Vorhaben, Polen zu isolieren. Auf der Suche nach Motiven tritt schlaglichtartig das irritierend Zwiespältige seines Wirkens zutage. Denn es ist keineswegs von der Hand zu weisen, daß der überzeugte Revisionist seine fragwürdigen propagandistischen Methoden auch deshalb anwandte, damit ungeachtet sonstiger aus nationalsozialistischer Aggression resultierender Feindseligkeiten wenigstens ein neuer deutsch-französischer Waffengang vermieden würde. Seinem beängstigend auf das bilaterale Verhältnis reduzierten Denken hätte ein solches Verhalten sehr wohl entsprochen. Seit Sohlbergzeiten war er darauf fixiert, Frieden zwischen den beiden Nationen zu stiften. Mit dieser Idee hatte er Karriere gemacht und sich im Strickwerk der Doppelmoral verheddert; nun war die bedingungslose Hingabe an die selbstgestellte Aufgabe zum kategorischen Imperativ geworden, der es erforderte, etwaige moralische Skrupel beiseite zu schieben. Seine propagandistische Tätigkeit konnte helfen, den drohenden Krieg zu gewinnen, ohne ihn im Westen führen zu müssen. Ob billige Selbstlegitimation oder verzweifelte Notbremse, der Anspruch, ein rundum integrer Freund Frankreichs zu sein, blieb in jedem Fall auf der Strecke. Die mit guten Gründen widerstrebenden Nachbarn sollten in den Jahren 1938/39 gleichsam überredet werden, um ihrer nationalen Sicherheit willen Hitlers Eroberungen zu dulden. Von gütlicher Konfliktregelung im Wortsinn konnte hierbei natürlich keine Rede sein - die

${ }^{84}$ Abetz, Das offene Problem, S. 95-103.

85 Ebenda, S. $103 \mathrm{f}$.

86 Unsignierte deutsche Aufzeichnung, die den Vorgang anhand von Berichten der Pariser Botschaft und französischen Pressemeldungen zusammenfaßt, Berlin 19. 7. 1939; PA/AA, R 29586. Phipps an Halifax, 30.6. 1939; DBFP, 3, VI, Nr. 186, nach persönlichen Mitteilungen Daladiers. 
Regierung Daladier sollte sich den Frieden am Rhein mit empfindlichen Positionsverlusten anderenorts erkaufen. Indem er diese Politik stützte, vollzog Abetz in seinem Verständnis von der Rolle Frankreichs einen entscheidenden Schritt hin zu jener Haltung, die ihn nach dem Westfeldzug die Degradierung und Umerziehung des besetzten Landes zum willfährigen, dafür wohlgelittenen Juniorpartner der europäischen Hegemonialmacht Deutschland befürworten ließ. Dessenungeachtet quälte ihn die Vorstellung, Deutsche und Franzosen aufeinander schießen $z \mathfrak{u}$ sehen. $\mathrm{Zu}$ wessen Lasten sich diese beiden Parteien arrangierten, war aber offenkundig zweitrangig. Sollten seine Landsleute einen Krieg anzetteln, eröffnete er im Oktober 1938 Henri Pichot, dann wünsche er inständig, daß sie es im Osten täten und Westeuropa, vor allem Frankreich verschont bliebe ${ }^{87}$. Mit anderen Worten: Marschierten Hitlers Divisionen ostwärts, dann war das bedauerlich, doch immerhin das kleinere Übel. In den Deutsch-Französischen Monatsheften wurde die Freundschaftserklärung vom 6. Dezember folgerichtig mit dem Hinweis gefeiert, sie schaffe „in einem begrenzten Raum Europas eine Beruhigung " 88 . Im Januar-Heft hieß es: „Europa ist um ein mögliches Schlachtfeld ärmer geworden." 89

Sollte alle Überzeugungsarbeit umsonst gewesen sein? Vehement bestritt Abetz lauter werdende Vorwürfe, die Deutschen hätten mit ihren Verständigungsofferten ein gigantisches Täuschungsmanöver inszeniert. Solchen Gedanken Raum zu geben, barg nicht zuletzt die Gefahr, das 1933 formulierte Ziel - Verständigung trotz Hitler - als Lebenslüge zu entlarven. Lieber klammerte er sich an ein Weltbild, das eine vermeintliche Kongruenz von Hitlers Worten und Taten gegenüber Frankreich suggerierte. Die deutsche Politik habe schlimmstenfalls die Beseitigung unhaltbarer Zustände in Europa beschleunigt, insistierte er im Juni 1939, die nationalsozialistische Strategie effektvoll umsetzend. Ein „so junges und so starkes Volk" wie das deutsche hätte die Ketten des Versailler Vertrags eines Tages ohnehin gesprengt, eine frühzeitige militärische Intervention Frankreichs diesen Prozeß höchstens um ein paar Jahre verzögert. Quasi als Gegenleistung für sein Stillhalten besitze Frankreich nun größtmögliche, nie dagewesene Sicherheiten, im besonderen „la neutralisation psychologique d'un peuple de 80 millions d'habitants à sa frontière de l'Est, le désir du peuple allemand et de la jeunesse allemande de vivre en paix avec ell ${ }^{\text {" } 90}$. Schon unmittelbar nach ,München" hatte er mit der Behauptung gelockt, die Franzosen genössen, dank der Vernunft einiger ihrer Staatsmänner, künftig den Schutz einer „moralischen Maginotlinie“ im Herzen der Deutschen ${ }^{91}$. War ein so märchenhafter Zustand am Rhein nicht ein Opfer an anderer Stelle, eine Aufteilung der politisch-ökonomischen Interessensphären nach deutschem Gusto wert? Ebendies suggerierten die Monatshefte, die potentiellen kompensatorischen Funktionen des Empire preisend, kaum daß die Sudetenkrise beigelegt schien. Sie bedienten sich wie üblich französischer Schützen-

87 Pichot, Et ce fut, pag. 84.

${ }^{88}$ Leitartikel „Zum Jahresende“, unsig.; DFM, Dezember 1938, S. 521.

89 Leitartikel „Pensées pour 1939“, unsig.; DFM, Januar 1939, S. 3. (beide Hervorhebungen durch den Verf.)

90 Abetz, Versailles, vingt ans après, in: DFM, Juni 1939, S. 354.

91 Ders., La victoire des vaincus?, in: DFM, Oktober 1938, S. 417. 
hilfe. Der bekannte Militärschriftsteller Jacques Benoist-Méchin nannte es "die große Lehre des Monats September“, daß man Männer nur für „wesentliche Ziele“ sterben lassen dürfe, „nicht für Dinge, die keine Lebensinteressen der Nation darstellen“. Diese ließen sich im übrigen "sehr wohl miteinander in Einklang bringen", meinte Méchin und steckte die Claims ab: Osteuropa galt ihm als deutsche, das östliche Mittelmeer als italienische Domäne; den Franzosen riet er zur „Entfaltung der großen Möglichkeiten, die im afrikanischen Imperium schlummern"92. Als die Danzig-Krise schwelte, empfahl ein gewisser Pierre Gardère eine säuberlich getrennte Hinwendung Frankreichs nach Übersee und Deutschlands gen Osten: „So sieht ein normales, berechenbares, ein logisches Europa aus.“ Auf diese Weise könnten die Franzosen ihr „Unterlegenheitsgefühl“, ihre „nervöse Empfindlichkeit“ überwinden und sich endlich wieder „freuen, wenn auch andere größer werden" ${ }^{\circ 93}$. Hitler selber signalisierte immer wieder Interesse an einem Modus vivendi mit den Westmächten, sofern sie ihm freie Hand in Polen gewährten 94 .

In der trügerischen Option, der drohende Krieg lasse sich auf das Reich und Polen beschränken, mag Abetz eine Chance erblickt haben, die ihm kostbaren deutsch-französischen Beziehungen vor einer tödlichen Zerreißprobe zu bewahren. Mußte er nicht erkennen, wohin die Entwicklung trieb und welch zweifelhafte Qualität ein unter solchen Vorzeichen gefundener "Ausgleich" mit Frankreich besessen hätte? Nach 1945 hielt er sich zu diesem Thema, wie zu vielen anderen, bedeckt - aus seiner Sicht verständlich angesichts der Tatsache, daß er in französischer Haft saß und kein Interesse haben konnte, seine Lage durch das Eingeständnis zu verschlimmern, sehenden Auges als Werkzeug für Hitlers Ablenkungsmanöver gedient zu haben. Er wollte seine Tätigkeit bis 1939 am liebsten als Beitrag zu einem „Wettlauf zwischen Krieg und Frieden“ gewertet wissen 95 . Seinen Richtern versicherte er: „Je cherchais, de toutes mes forces, avec la dernière vigueur, à influencer, dans les deux pays, du reste, dans un sens, une solution à l'amiable du conflit du couloir de Dantzig." nicht verborgen blieb, enthüllt die schon zitierte Denkschrift vom Juli 1940, die eine Usurpation des Friedensgedankens durch das nationalsozialistische Deutschland zum Zwecke einer moralischen Schwächung Frankreichs verzeichnete ${ }^{97}$.

92 Jacques Benoist-Méchin, Deutsches und französisches Soldatentum, in: DFM, November 1938, S. 475-492. Es handelt sich um den Abdruck eines historisierenden Vortrags, den Méchin am 10. November zum 20. Jahrestag des Waffenstillstands von Compiègne im Berliner DFG-Haus hielt. Er wiederholte ihn am 26. November anläßlich der Gründung einer DFG-Sektion „Württemberg“ in Stuttgart. Vgl. DFM 1938, S. 519, 594.

93 Pierre Gardère, Die Nachbarreiche, in: DFM, Juni 1939, S. 356-359.

94 Noch auf dem Höhepunkt der Augustkrise unterbreitete er, in gewohnter Manier auf die deutsche Ehre und Gleichberechtigung abhebend, fragwürdige Kompromißangebote, z. B. in einem Brief an Daladier vom 27.8. 1939, abgedruckt bei Domarus, Hitler, II, S. $1273 \mathrm{ff}$. Dem britischen Botschafter Henderson offerierte er am 25. August für ein Entgegenkommen in der Polenfrage deutsche Waffenhilfe zum Schutz des Empire; ebenda, S. 1257.

95 Abetz, Das offene Problem, S. 59.

96 Abetz-Prozeß, 12. 7. 1949, pag. 22; AN, 334 AP 49.

97 Abetz, "Politische Arbeit in Frankreich“, pag. 11; CDJC, LXXI-28. 
Der Versuch, das deutsch-französische Verhältnis aus dem sich zuspitzenden Konflikt herauszuhalten, mußte schon deshalb fehlschlagen, weil es Hitler nicht einfiel, Verständigung um ihrer selbst willen zu treiben. Seine Offerten dienten dem strategischen Zweck, einen Zweifrontenkrieg zu vermeiden; der programmatische Vorsatz, früher oder später mit Frankreich abzurechnen, blieb davon unberührt. Abetz' Danzig-Kampagne war von der NS-Führung mithin als offensive, den Polenfeldzug vorbereitende Maßnahme intendiert ${ }^{98}$ und wurde von Daladier auch so bewertet. Prompt wurde Abetz in Frankreich zur persona non grata erklärt. Eine Affäre nahm ihren Lauf; die nähere Betrachtung lohnt, weil sie sowohl den eingetretenen Wandel im zwischenstaatlichen Umgangston als auch die Perzeption der nationalsozialistischen Friedenspropaganda im Jahre 1939 und ihre Tiefenwirkung in Frankreich dokumentiert.

\section{Grünes Licht für die Abwehr: Abetz wird persona non grata}

Französischen Staatsschützern bot sich eine willkommene Gelegenheit, gegen einen Mann vorzugehen, den sie dringend kaltzustellen wünschten. Abetz galt ihnen als führender Kopf einer großen Schar ebenso charmanter wie heimtückischer Brunnenvergifter, die in einer halboffiziellen Grauzone arbeiteten und das Recht auf freie Meinungsäußerung mißbrauchten, um die Öffentlichkeit zu manipulieren. „La propagande nazie s'infiltre chez nous comme l'eau dans le sable [...] elle divise de plus en plus les Français, neutralise leur esprit de résistance, alimente les foyers de discorde", so die beredte Klage Paul Pailloles von der DeutschlandAbteilung des Deuxième Bureau. Er hielt diese sanfte Tour der Zersetzung längerfristig für weitaus gefährlicher als etwa die Tätigkeit gewöhnlicher Spione99. Während letztere der französischen Abwehr zuhauf ins Netz gingen - $274 \mathrm{im} \mathrm{Jahr}$ 1938, über 300 allein im ersten Halbjahr 1939 - und strafrechtlich zu belangen waren, fehlte es zum Leidwesen der Fahnder aber lange Zeit an wirksamen juristischen Handhaben, um Propagandisten vom Schlage eines Otto Abetz beizukommen. Die Politiker, bemängelten sie, nahmen das Problem auf die leichte Schulter oder bremsten Gegenmaßnahmen aus Furcht vor außenpolitischen Verwicklungen $^{100}$. Die Exekutive, so Paillole, sei sich der „unheilvollen Macht“ jener Agitation nicht hinreichend bewußt geworden; gegen eine Ausweisung Abetz' hätten sowohl Bonnet wie Daladier Einwände erhoben ${ }^{101}$. Auch an öffentlich vorgetra-

\footnotetext{
98 Vgl. Coulondre an Bonnet, 1. 6. 1939; DDF, 2, XVI, Nr. 326.

99 Paillole, Services spéciaux, S. 107, $111 \mathrm{ff} ., 146$.

100 Ebenda, S. 117. Vgl. Navarre, Le service des renseignements, S. 88, 93; Paillat, Le désastre de 1940, I, S. 305.

101 Schriftl. Mitteilung an den Verf. vom 11. 4. 1993. Laut Paillole wurde das Archiv seiner Dienststelle, einschließlich der Berichte über die „tödliche Gefahr “ der NS-Propaganda jener Jahre, zuerst von der Wehrmacht, dann von sowjetischen Truppen erbeutet. Seit geraumer Zeit bemüht sich der Oberst a. D. um eine Rückgabe der Bestände - möglicherweise ergeben sich hier noch neue Erkenntnisse.
} 
gener Kritik gegen diese laxe Haltung hat es nicht gefehlt: „On sait bien que cette propagande a fait et fera des ravages dans notre pays", tadelte etwa de Kerillis. „Mais on se tait. On refuse de voir et de savoir [...] Tant pis si le silence devient une complicité!" 102 Dabei darf freilich nicht übersehen werden, daß die französische Diplomatie die Aktivitäten der Dienststelle Ribbentrop über Jahre hinweg als durchaus nützliches Hilfsmittel bewertet hat, um unerwünschte Spannungen im deutsch-französischen Verhältnis abzumildern.

Erst als sich die gegenseitigen Beziehungen rapide verschlechterten, fanden die Warnungen der Sicherheitsexperten Gehör. Sie erhielten zunächst grünes Licht für eine Aktion gegen deutsche Journalisten, die subversiver Umtriebe verdächtig waren. Großes Aufsehen erregte die Verhaftung von Heinrich Baron, Korrespondent der Berliner Börsenzeitung, und seiner Frau Anfang Februar 1939, nachdem man ihnen telefonische Kontakte zu Geheimdienststellen im Reich nachgewiesen hatte. Baron war seit Januar 1935 als Nachfolger Eugen Feihls, der als Presseattaché zur Botschaft wechselte, in Paris tätig. Er räumte ein, in Verbindung mit der Abwehrstelle Münster/Westfalen zu stehen. Dorthin übermittelte er im Rahmen seiner Berufstätigkeit erlangte Informationen über die Armee und politische Lagebeurteilungen ${ }^{103}$. Fast zum selben Zeitpunkt scheiterte der Versuch Himmlers, einen SD-Vertreter als Polizei-Attaché an der Botschaft zu installieren, am Veto der französischen Einreisebehörden. Vier weitere Zeitungsleute wurden festgenommen oder des Landes verwiesen ${ }^{104}$. Am 11. Februar protestierte Botschafter Welczeck im Namen der Reichsregierung gegen diese Maßnahmen, die nach dem Stand der Ermittlungen völlig ungerechtfertigt seien, und drohte Vergeltung an ${ }^{105}$. Seine Demarche blieb wirkungslos. Eine Serie von Dekreten schränkte die Informationsfreiheit im Lande ein. Ende April verbot die Pariser Regierung mehrere autonomistische Ligen im Elsaß, die vom Bund Deutscher Westen, einer der Volksdeutschen Mittelstelle angegliederten Organisation, kontrolliert wurden ${ }^{106}$. Vage Befürchtungen, die Nation sei nationalsozialistisch unterwandert, steigerten sich im Lauf des Frühjahrs allmählich zu einer durch alarmierende Presseberichte angeheizten Massenpsychose. Vorneweg segelte wieder einmal Henri de Kerillis, der in seinem Blatt die Furcht vor einem unsichtbaren, aber allgegenwärtigen, allwissenden deutschen Überwachungsapparat schürte, vergleichbar unseren heuti-

102 "La propagande allemande est multiforme mais admirablement camouflée“, in: L'Epoque, 27. 5. 1939.

103 Heinrich Franz Baron, Jg. 1900, brach Mitte der zwanziger Jahre ein Studium zum Bergbau-Ingenieur zugunsten einer journalistischen Laufbahn ab. Er und seine Frau Katharina wurden nach Kriegsbeginn wegen Spionage zum Tode verurteilt, jedoch 1940 von deutschen Soldaten befreit. Danach arbeitete Baron, Mitglied der „Abteilung VII/Ausland“ im Reichspropagandaministerium, als Korrespondent in Lissabon. Feihl zufolge war er antinazistisch orientiert; über seine Berichte habe die Botschaft verhaltene Kritik an der deutschen Politik äußern können. Vgl. Protokoll einer polizeilichen Vernehmung Barons am 8. 2. 1939; AN, F 1a/3749. Angaben Feihls gegenüber der Sûreté Nationale, Protokoll Nr. 149/15 vom 1. 9. 1946; AN, 3 W 358, Dossier Feihl.

104 Paillole, Services spéciaux, S. $110 \mathrm{f} ., 137 \mathrm{f}$.

105 Vermerk Bonnets vom 11. 2. 1939; MAE, Papiers 1940, Cabinet Bonnet/1.

106 Kupferman, Diplomatie parallèle, S. 94; Jacobsen, Außenpolitik, S. 245. 
gen Vorstellungen von der Stasi-Krake und ihren ,Informellen Mitarbeitern ${ }^{107}$. Aus Sicht der französischen Abwehr war dies ein günstiger Moment, um Abetz auszuschalten. Anlaß für energische Schritte bot sein Verhalten im mittlerweile voll entbrannten Nervenkrieg um Danzig.

Die polnische Regierung hatte sich im Winterhalbjahr 1938/39 standhaft geweigert, Hitlers Forderungen - Rückkehr Danzigs zum Reich, exterritoriale und zu Deutschland gehörige Auto- und Eisenbahn durch den Korridor, Beitritt Polens zum Antikominternpakt und anderes mehr - zu akzeptieren ${ }^{108}$. Seither mußte damit gerechnet werden, daß der Diktator erneut zu gewaltsamen Mitteln griff. Die anglo-französische Garantie vom 31. März 1939, die Danzig de facto einschloß, internationalisierte das Problem entgegen seinen Wünschen ${ }^{109}$. Aber würden die Westmächte ihren Verpflichtungen im Ernstfall tatsächlich nachkommen? Vielleicht ließ sich das verhindern. „Nous devons [...] nous attendre dans les semaines qui vont suivre à une violente offensive contre l'armature morale de la France et de l'Angleterre", warnte der französische Geschäftsträger in Berlin, de Vaut SaintCyr, am 6. April. Die deutsche Propaganda werde alles daran setzen, die gegnerische Kampfbereitschaft zu schwächen und Keile zwischen die Verbündeten zu treiben, und eben diesem Zweck diene höchstwahrscheinlich auch der jüngste Aufenthalt von Otto Abetz in Paris 110. Äußerer Anlaß hierfür waren die Auflösungserscheinungen im Comité France-Allemagne. Abetz wollte versuchen, „die Sache einzurenken"111. Nachdem dieses Vorhaben gescheitert war, tingelte er, um Freundschaft und Vertrauen werbend, in Begleitung seiner Frau durchs Land ${ }^{112}$.

Unterdessen registrierten aufmerksame Beobachter, daß systematisch Angehörige von SS und Wehrmacht, als Touristen getarnt, nach Danzig eingeschleust wurden. Man argwöhnte, Hitler bereite einen „kalten Anschluß“ vor, eine von Berlin aus gesteuerte Erhebung der Danziger Bevölkerung, die die Vereinigung mit dem Reich erzwingen sollte ${ }^{113}$. Auf diese Weise konnte Hitler Polen unter Druck setzen und sich, wenn etwas schieflief, elegant aus der Verantwortung ziehen. Ende Juni verdichteten sich die Anzeichen, daß der kritische Moment nahe war. „Il semble [...] que les préparatifs militaires du Reich dans la Ville libre aient

107 „La machine allemande est si formidable, elle a enchevêtré et confondu tant de choses, si bien lié malgré eux des braves gens à des traîtres avérés, si bien enchaîné les uns aux autres tant de vastes intérêts avouables ou non avouables, que tout le monde est comme frappé de paralysie. On a peur d'atteindre, sans le vouloir, un voisin et un ami. On a peur de découvrir avec horreur que soi-même on est tombé sans le savoir dans le filet de l'ennemi." Kerillis, La propagande allemande, L'Epoque, 27. 5. 1939.

108 Vgl. ADAP, D V, Nr. 81, 101, 119, 120, 126; D VI, Nr. 61, 101.

109 Hierzu Bernd-Jürgen Wendt, Danzig - Ein Bauer auf dem Schachbrett nationalsozialistischer Außenpolitik, in: Funke (Hrsg.), Hitler, S. 793.

110 Saint-Cyr an Bonnet, 6. 4. 1939; DDF, 2, XV, Nr. 281.

111 Saint-Cyr an Bonnet, 4. 4. 1939, ebenda, S. 477, Anm. 1.

112 Theodore Draper, Nazi Spies in France, in: New Republic, 23. 8. 1939, S. 72. Daß Abetz im Frühjahr 1939 über längere Zeiträume in Frankreich weilte, läßt sich auch der amtlichen Verlautbarung in Le Temps vom 30. Juni entnehmen, wonach er sich, im Laufe der letzten Wochen" mit den französischen Interessen schädlichen Aktivitäten hervortat.

113 Vgl. Coulondre an Bonnet, 27. 6. 1939; DDF, 2, XVII, Nr. 12 und 13 sowie S. 67, Anm. 6. Bonnet, Vor der Katastrophe, S. 235. 
pris un rythme accéléré", meldete Botschafter Coulondre besorgt ${ }^{114}$. Er erwartete spätestens für August eine Teilmobilmachung der Wehrmacht und eine Machtprobe ähnlich wie im vergangenen Jahr ${ }^{115}$. Die allgemeine Beunruhigung wurde noch verstärkt durch die Tatsache, daß die Bündnisverhandlungen des Westens mit der Sowjetunion in einer Sackgasse steckten. Am 29. Juni erschien in der Prawda ein Aufsehen erregender Artikel von Politbüro-Mitglied Schdanow, der nur geringes Interesse an einer Allianz bekundete ${ }^{116}$. England und Frankreich mußten befürchten, daß sich Stalins Mißtrauen ihnen gegenüber verfestigte, wodurch eine deutsch-sowjetische Annäherung womöglich erleichtert wurde, gewiß aber Hitlers Entschluß zum Angriff auf Polen ${ }^{117}$. So lagen in Europas Schaltzentralen die Nerven einige bange Tage lang bloß. Erst Anfang Juli wich die Anspannung, setzte sich die Erkenntnis durch, daß bezüglich Danzig zumindest keine akute Gefahr mehr drohte und die Reichsregierung wohl nur einen Versuchsballon gestartet hatte, um Reaktion und Kampfbereitschaft der potentiellen Gegner zu testen ${ }^{118}$.

Die Franzosen demonstrierten Standfestigkeit. Daladier beendete die Sitzungsperiode des Parlaments am 27. Juni mit dem flammenden Appell, sich mit allen Kräften gegen Versuche zu stemmen, die bestehenden Verhältnisse in Europa umzustürzen. „S'armer, s'unir, veiller, voilà le devoir présent." Scharf verurteilte er propagandistische Kampagnen, die Uneinigkeit stiften sollten und deren ausländische Urheberschaft erwiesen sei119. Der Ministerpräsident, so Welczecks Erkenntnis, sei „vollständig in das Lager der ,Antimünchner ' hinübergewechselt“; er wolle offenbar durch kompromißloses Gebaren eine gewaltsame Aktion der totalitären Staaten verhindern, die ein französisches Eingreifen notwendig machen würde ${ }^{120}$. Auch Coulondre empfahl eine „attitude d'extrème fermetéc vis-à-vis Berlin ${ }^{121}$. Bonnet versuchte zumindest, den Anschein von Härte zu erwecken. Frankreich müsse eine „unbeugsame Entschlossenheit“ an den Tag legen, seine Verpflichtungen in Osteuropa zu erfüllen, notierte der Außenminister am 1. Juli;

114 Coulondre an Bonnet, 28. 6. 1939; DDF, 2, XVII, Nr. 27.

115 Vermerk Bonnets über eine Unterredung mit Coulondre, 24. 6. 1939; MAE, Papiers 1940, Cabinet Bonnet/1.

116 Siehe DDF, 2, XVII, Nr. 56 und 110. Der deutsche Botschafter in Moskau, Schulenburg, wertete den Artikel als mögliche Replik auf einen Kommentar in Le Temps vom 24. Juni. Darin hieß es, daß Rußland seine Verschleppungstaktik fortsetze, obwohl Frankreich und Großbritannien ihren guten Willen bei den Verhandlungen bewiesen hätten. ADAP, D VI, Nr. 582.

$117 \mathrm{Vgl}$. Coulondre an Bonnet, 1.6. 1939: „On pense qu'il risquera la guerre s'il n'a pas à combattre la Russie“; DDF, 2, XVI, Nr. 326.

118 Coulondre an Bonnet, 4. 7. 1939; DDF, 2, XVII, Nr. 91,92 und 95.

119 Ebenda, S. 165, Anm. 1. Schulthess' 80 (1939), S. 438, zit. Daladier mit den Worten: „Im Innern unseres Landes entfaltet sich eine äußerst tätige Propaganda, um die Franzosen zu entzweien und die Solidarität Frankreichs und Englands zu brechen, ohne die nach meiner Ansicht keine große Hoffnung mehr auf die Freiheit der Welt bliebe [...] Wir haben die Überzeugung gewonnen, daß ein Versuch gemacht worden ist, Frankreich in einem Netz von List, Spionage und noch Schlimmerem einzufangen.“

120 Welczeck an Auswärtiges Amt, 1. 7. 1939; PA/AA, Botschaft Paris 1156c.

121 Vermerk Bonnets vom 24. Juni, wie Anm. 115. 
jedes Mißverständnis diesbezüglich könne unübersehbare Folgen zeitigen ${ }^{122}$. Schon Anfang Juni aber hatte Coulondre gemeldet, deutsche Diplomaten seien instruiert worden, Gerüchte zu verbreiten, daß die Westmächte sich für Danzig nicht schlagen würden ${ }^{123}$. Und genau diese Meinung vertrat Otto Abetz in den letzten Junitagen, als die Situation zum Zerreißen gespannt war, bei seinen zahlreichen Pariser Bekannten. Etliche von ihnen erstatteten Bericht beim Innenministerium, bei der Polizei, der Sûreté oder beim Ministerpräsidenten persönlich ${ }^{124}$. Daladier war empört und offenbar entschlossen, ein Exempel zu statuieren. Wer wollte noch ernsthaft bezweifeln, daß Abetz auf höheren Befehl handelte, ein Agent provocateur war?

Am Morgen des 30. Juni informierte der aufgebrachte Ministerpräsident Bonnet über seine Absicht, sofort einen Ausweisungsbefehl zu erlassen. Bonnet jedoch warf ein, in Anbetracht der "tension actuelle" wäre es ratsamer, Abetz zur freiwilligen Abreise zu bewegen. Mit Daladiers Zustimmung will er dann Graf Welczeck den Sachverhalt geschildert und angeregt haben, Abetz solle das erste Flugzeug nach Berlin nehmen, um sich weiteren Ärger zu ersparen ${ }^{125}$. Im gleichen Sinne wirkte eine Ebene tiefer Kabinettschef Pierre Bressy auf Botschaftsrat Bräuer ein. Bressy begründete die gegen Abetz eingeleiteten Schritte damit, daß dieser „, in den letzten Tagen eine Anzahl von französischen Persönlichkeiten aufgesucht und ihnen bei dieser Gelegenheit in sensationeller Weise einen bevorstehenden deutschen Handstreich auf Danzig angekündigt" habe. Seine Äußerungen würden in verschiedenen Varianten wiedergegeben, welche aber im Tenor übereinstimmten. Mehreren Zeugen zufolge nannte er als konkretes Angriffsdatum den 1. Juli. In der planmäßigen Verbreitung solcher Gerüchte sehe die französische Regierung den Tatbestand einer nach den neuesten Verordnungen verbotenen Propaganda erfüllt. Ministerpräsident Daladier habe deshalb persönlich den Erlaß eines Ausweisungsbefehls angeordnet. Der Chef des Quai d'Orsay seinerseits lege "großen Wert" darauf, daß dieser Befehl nicht vollstreckt werde; man möge deshalb Abetz nahelegen, Frankreich umgehend zu verlassen ${ }^{126}$.

Deutlich wird hier das Bemühen Bonnets erkennbar, nicht unnötig Staub aufzuwirbeln, sondern die heikle Angelegenheit möglichst im stillen zu bereinigen. Obwohl sein Appeasementkurs seit dem deutschen, Griff nach Prag' vor der Öffentlichkeit und im Kabinett völlig diskreditiert war und er äußerlich auf Daladiers Linie der Stärke einschwenkte, hielt er "verdeckt“ an seiner konzessionsbe-

122 Vermerk Bonnets vom 1. 7. 1939; MAE, Papiers 1940, Cabinet Bonnet/1. Die zitierten Wendungen sind wörtlich enthalten in einer Note der französischen Regierung, die Bonnet am selben Tag Welczeck übergab; abgedruckt ADAP, D VI, Nr. 602.

123 Coulondre an Bonnet, 1. 6. 1939, wie Anm. 117.

124 Nach Angaben von Bonnets Kabinettschef Bressy. Aufzeichnung des Auswärtigen Amtes vom 19.7. 1939; PA/AA, R 29586.

125 Bonnet, Dans la tourmente, S. $157 \mathrm{f}$. Die hier behauptete Unterredung mit Welczeck ist allerdings weder in den deutschen noch französischen Akten belegt. Die beiden Diplomaten konferierten nachweislich am 1. Juli, freilich ohne den Fall Abetz anzuschneiden. Bonnet nennt in seinen Erinnerungen auch kein Datum. Daß die Affäre am 30. Juni ins Rollen kam, geht indes zweifelsfrei aus anderen Dokumenten hervor.

126 Aufzeichnung des Auswärtigen Amtes, 19. 7. 1939; PA/AA, R 29586. 
reiten Deutschlandpolitik fest ${ }^{127}$. Er bevorzugte vergleichsweise leise Töne und wollte es vermeiden, die deutsche Seite zu reizen. Im Gespräch mit Welczeck warb er Mitte Mai 1939 um Verständnis für den erlittenen „Vertrauensschock“ der Franzosen. „Der Mann auf der Straße sei es eben satt, alle Augenblicke aus der Zeitung einen neuen Gewaltcoup zu erfahren und in ständiger Unruhe zu leben." Er persönlich werde aber den „Gedanken einer wieder ins Geleise kommenden, sich mit der Zeit enger gestaltenden Zusammenarbeit mit Deutschland" nicht fallenlassen und sei „immer bereit" dazu128. Daß eine solche Einstellung die von Sicherheitsexperten wie Paillole und Journalisten wie de Kerillis kritisierte Laxheit im Umgang mit nationalsozialistischer Agitation begünstigte und auch Otto Abetz noch geraume Zeit Entfaltungsmöglichkeiten eröffnete, erscheint evident. Nicht von ungefähr hatte Bonnet in den voraufgegangenen Monaten mehrmals zugunsten von Reichsangehörigen interveniert, denen die Ausweisung drohte ${ }^{129}$.

Botschaftsrat Bräuer legte sofort "schärfste Verwahrung" gegen die Abschiebung von Abetz ein und beteuerte, jener habe in Paris lediglich Gespräche über das weitere Schicksal des Comité France-Allemagne führen wollen. Bei der momentan herrschenden Nervosität könne sich jedoch kein Deutscher, der mit Franzosen zusammenkomme, Fragen zum Schicksal Danzigs entziehen. Abetz' Äußerungen hätten „sicher nur so viel bedeutet, $\mathrm{da} ß$ wir [...] Vertrauen auf unser gutes Recht hätten und die Frage Danzig eines Tages in unserem Sinne gelöst werden müsse". Im übrigen habe sich Abetz im Laufe des Vormittags auf der Botschaft verabschiedet und sei bereits abgereist ${ }^{130}$. Durchatmen im Quai d'Orsay - es schien so, als ließe sich die Sache problemlos regeln. Einige Journalisten aber hatten Wind davon bekommen. Le Temps meldete in der Abendausgabe vom 30. Juni: „Un arrêté d'expulsion vient d'être pris contre un sujet allemand, mandataire des services de propagande du gouvernement du Reich et qui s'est signalé, au cours de ces dernières semaines, par son activité contre les intérêts de la France. "131 Daß das regierungsnahe Blatt keinen Namen nannte, unterstreicht nur Bonnets Absicht, jedes Aufsehen zu vermeiden. Anderseits wurde gerade hierdurch die Neugier der Öffentlichkeit angestachelt, wie die Pariser Tageszeitung hervorhob ${ }^{132}$. Die Behörden weigerten sich, die Identität des Delinquenten preiszugeben ${ }^{133}$, doch schon zwei Tage später war das Geheimnis gelüftet: „Le sujet allemand expulsé [...] est M. Abetz", verkündete triumphierend die Zeitung L'Epoque und sprach von einem längst überfälligen Schritt. Henri de Kerillis, der seine Landsleute seit Jahren unablässig vor der nationalsozialistischen Gefahr

127 Überzeugend dargelegt und dokumentiert von Bellstedt, „Apaisement“ oder Krieg, S. 242-254.

128 Welczeck an Auswärtiges Amt, 20. 5. 1939; ADAP, D VI, Nr. 409.

129 Ebenda, S. 448, Anm. 2.

130 Wie Anm. 126. Daladier zufolge fiel die Bemerkung, Abetz sei wichtiger als der Botschafter: „Chargé d'Affaires [Bräuer] professed to be horrified and said Abetz was more important than the Ambassador." Phipps an Halifax, 30. 6. 1939; DBFP, 3, VI, Nr. 186.

131 Le Temps, 30. 6. 1939, abends.

132 Pariser Tageszeitung, 2./3. Juli.

133 L'Epoque, 1. 7. 1939. 
warnte ${ }^{134}$, beschrieb den Ribbentrop-Emissär als perfiden Propagandisten und Nachrichtendienstler mit ergiebigen Informationsquellen bis in die Vorzimmer von Ministerien hinein ${ }^{135}$.

\section{5. „Les nazis sont-ils maitres chez nous?“ Panik vor Spionen und Sabotage}

Damit trat de Kerillis eine Lawine los. Sensationell aufgemachte Presseberichte in den folgenden Wochen dämonisierten Abetz als gerissenen Meisteragenten, der den Wehrwillen der Nation systematisch untergraben habe ${ }^{136}$. Er wurde als „Seele der deutschen Propaganda in Paris" 137 bezeichnet, als „Spion, der Frankreich mit allen Mitteln geschadet hat" ${ }^{138}$, in ultimativer Steigerung und besonders schlagzeilenträchtig gar als „Superspion“ 139 . Die Kolumnisten bescheinigten ihm „mephistophelische" Verschlagenheit ${ }^{140}$, rieben sich an seinem weltmännischen Habitus und verführerischen Charme, Eigenschaften, die es ihm erleichtert hätten, eine „schlichtweg erstaunliche“ Anzahl hochrangiger Persönlichkeiten kennenzulernen, auszuhorchen und zu beeinflussen ${ }^{141}$. Es hieß, er habe Parlamentarier und Industrielle, Journalisten und Intellektuelle korrumpiert und sich „mit bemerkenswertem Erfolg“ der Aufgabe gewidmet, die Franzosen zu entzweien und zu demoralisieren ${ }^{142}$. Manche brüsteten sich, seit Jahren vor seinem verderblichen Tun zu warnen, und attestierten der Pariser Regierung einen „Langmut, der an Idiotie grenzt "143. Auch erblickte man in Abetz nur die Spitze des Eisbergs, den heimlichen Gebieter über ein Heer von Kundschaftern, Informanten und üppige Bestechungsgelder verteilenden Helfershelfern ${ }^{144}$. „Les nazis sont-ils maîtres chez nous?" fragte ein besorgter Schreiber ${ }^{145}$, und vielstimmig erscholl der Ruf, mit eisernem Besen auszukehren.

Einzig Jean Luchaire - wer sonst - brach eine Lanze für den Verfemten: „On a traité Abetz d'espion, ce qui est indigne. On l'a accusé d'avoir disposé de traitements gigantesques, ce qui est risible [...] Bref, on a imprimé la plus stupéfiante avalanche de sottises, de mensonges, d'âneries qui se puisse imaginer." Dabei exi-

134 Siehe etwa Kerillis, Français, voici la guerre!, Paris 1936.

135 L'Epoque, 2. 7. 1939.

136 Sammlungen von Presseausschnitten hierzu in den Pariser Archives Nationales, 72 AJ 465/3 und 602. Die für unser Thema wichtige Zeitung L'Epoque ist, auf Mikrofilm archiviert, in der Bibliothèque de Documentation Internationale Contemporaine (BDIC) in Paris-Nanterre leicht zugänglich.

137 Le Journal, 15. 7. 1939.

138 Aux Ecoutes, 8. Juli.

139 L'Epoque, 10. Juli und 11. August.

140 L'Indépendent, 13. August.

$141 \mathrm{Le}$ Cri de Paris und L'Epoque vom 9. Juli.

142 La Lumière, 14. Juli; L'Epoque, 5., 9. und 16. Juli.

143 L'Action Française, 16./17. Juli.

144 L'Ordre, 8. Juli, wo der Fall Abetz unter der Rubrik „L'homme du jour“ behandelt wurde. L'Epoque, 11. Juli.

145 André Stibio in L'Ordre, 11. Juli. 
stiere doch lediglich eine „Einladung“, Frankreich zu verlassen, wo Abetz’ Aufenthalt "vorübergehend für inopportun" gehalten werde. Luchaire wollte eine „von der Humanité, Kerillis [!] und anderen Verteidigern einer französischen Unterwerfung unter sowjetische Gebote" lancierte Kampagne erkennen ${ }^{146}$. Mit seiner verharmlosenden, die Kommunisten zu Sündenböcken stempelnden Sicht stand er freilich allein auf weiter Flur und bezog, wie zu erwarten, Prügel. Paul Nizan etwa verlangte bündige Aufklärung darüber, ob Luchaire als „bezahlter Agent" Deutschlands zu gelten habe ${ }^{147}$; Kerillis rechnete Notre Temps zu jenen Organen, die den Spion Abetz durch Schweigen oder tendenziöse Berichterstattung zu decken versuchten ${ }^{148}$. Bereits am 7. Juli hatte La Lumière gefordert, Notre Temps solle Konten und Einnahmequellen offenlegen. Unmittelbar nach dem Einsatz für Abetz mußte Luchaire, an Tuberkulose erkrankt, ein Sanatorium aufsuchen, seine Zeitung, von Gläubigern bedrängt, das Erscheinen vorläufig einstellen. Wie es scheint, beschied der Quai d'Orsay einen Hilferuf um zusätzliche finanzielle Unterstützung abschlägig ${ }^{149}$.

Die Abetz-Affäre zog Kreise und gab den Anstoß zu weiteren Enthüllungen. Wer immer näheren Umgang mit ihm gepflegt hatte, schien zumindest der geistigen Komplizenschaft mit Hitler-Deutschland überführt und verdächtig, ein Wegbereiter des Defätismus, womöglich ein Landesverräter zu sein. Langjährige Bekannte gingen vorsichtig auf Distanz, so das frühere CFA-Vorstandsmitglied Henry-Haye. Von de Kerillis befragt, ob er Schritte zur Aufhebung der gegen Abetz verhängten Maßnahmen unternommen habe, antwortete er mit einem "glatten Nein“. Vergeblich empfahl Botschafter Welczeck den Senator bei Daladier als Bürgen für Abetz' lautere Absichten ${ }^{150}$. Eine allgemeine Panik vor Spionen und Saboteuren erfaßte die Nation, die Gerüchteküche brodelte. Die britische Botschaft in Paris erfuhr vom Deuxième Bureau, Verästelungen der NS-Propaganda erstreckten sich ,in alle Lebensbereiche“ 151 . Abetz hatte sich angeblich vor kurzem mit falschem $\mathrm{Paß}$ in London aufgehalten, um das dortige nationalsozialistische Spionage- und Propagandanetz zu reorganisieren ${ }^{152}$. Paul Ferdonnet, ehemaliger Chef der Nachrichtenagentur Prima, beschuldigt, deutsche Schmiergelder

146 Notre Temps, 15. und 16. Juli.

147 Ce Soir, 15. Juli.

148 „Et maintenant, vive Abetz!“ L'Epoque, 24. Juli.

149 Les procès de collaboration, S. 354, 368. AN-Enquête, IX, S. 2609 (Aussage Bonnet). Notre Temps erschien erneut im März 1940, dank tätiger Zuwendung des Informationsministers Frossard. Luchaires Nibelungentreue zu Abetz sollte sich unter deutscher Besatzung - auch im Wortsinn - auszahlen. „Je lui ai gardé une profonde reconnaissance de cette attitude loyale, amicale et courageuse qui devait lui fermer bien des portes“, sagte der Ex-Botschafter im Zeugenstand. Les procès de collaboration, S. 490.

150 L'Epoque, 7. und 8. Juli. Aufzeichnung des Auswärtigen Amts vom 19. Juli; PA/AA, R 29586.

151 Campbell an Foreign Office, 31. 7. 1939; zit. bei Adamthwaite, France, S. 332. Vgl. de Monzie, Ci-devant, S. 127f., 130f., dem ersichtlich zuviel Aufhebens um die Sache gemacht wurde: „Quiconque a fréquenté $M$. Abetz, doit être tenu pour suspect. Fernand de Brinon est le centre de cette suspicion [...] J'ai le dégoût de cette curée morale que provoque chaque crise de la patrie."

152 L'Epoque, 18. Juli. 
zu verteilen, darüber hinaus mit hitlerfreundlichen, antisemitischen und die Liquidierung der Tschechoslowakei rechtfertigenden Publikationen ins Fadenkreuz der Fahnder geraten, entzog sich drohender Strafverfolgung durch fluchtartige Abreise ausgerechnet nach Berlin. Nach Kriegsbeginn suchte er als Mitarbeiter einer von Stuttgart aus betriebenen Radiostation die französische Kampfmoral zu schwächen ${ }^{153}$. Daladier stellte in einer amtlichen Erklärung vom 15. Juli zwar fest, daß unkorrekte, zum Teil unhaltbare Behauptungen kursierten, und rief speziell der Presse in Erinnerung, daß bewußte Falschmeldungen und Eingriffe in schwebende Ermittlungsverfahren durch unautorisierte Verbreitung von Nachrichten strafbar seien. Gleichzeitig aber kündigte er eine gründliche Untersuchung und Säuberung an; die Justiz werde ohne Ansehen der Person gegen jede vom Ausland gesteuerte Korruption und Agitation vorgehen ${ }^{154}$. Auch er wähnte Frankreich überzogen von einem „Netz aus List, Spionage und Schlimmerem“155. Ein vertraulicher Bericht für den Regierungschef verzeichnete für den Zeitraum von Juni bis September die Aufdeckung von 150 Spionagefällen und damit einhergehend über 250 Festnahmen ${ }^{156}$. Die aufgeschreckte Öffentlichkeit sah sich massiv in der Befürchtung bestätigt, daß das „Krebsgeschwür“ nationalsozialistischer Infiltration in wichtigen Nervenzellen der Gesellschaft wuchere ${ }^{157}$.

Besonderes Aufsehen erregte die Verhaftung zweier Pressevertreter in leitenden Positionen am 12. Juli. Loys Aubin, Nachrichtenchef von Le Temps, Offizier der Ehrenlegion, und Julien Poirier, bewährter Anzeigenverkäufer des Figaro, waren geständig, für die Deutschen gearbeitet zu haben ${ }^{158}$. Aubin (66), der angeblich viel Geld in Antiquitäten und Pferdewetten investierte, soll für die verdeckte Verbreitung nationalsozialistischer Propaganda über einen Mittelsmann Goebbels' mehr als vier Millionen Francs erhalten haben; er wurde im Mai 1940 zu zehn Jahren Gefängnis verurteilt. Poirier (69), der offenbar gern an der Börse spekulierte, soll mit ähnlichen Summen entlohnt worden sein; er starb wenige Tage nach seiner Enttarnung an den Folgen einer Darmoperation ${ }^{159}$. Ein enger Zusammenhang mit der Ausweisung von Abetz, dem rege finanzielle Einflußnahme gerade im Pressemilieu nachgesagt wurde, drängte sich auf und wurde lebhaft diskutiert. „Herr Abetz wurde mit Namen in fast allen Pariser Blättern mit dieser Bestechungs-

153 Les procès de la radio. Ferdonnet et Jean Hérold-Paquis, S. 12f., 21 ff.; Paillole, Services spéciaux, S. 137; Gallo, La cinquième colonne, S. $24 \mathrm{f}$.

154 Vgl. die Pariser Tagespresse vom 16./17. Juli.

155 Zit. in Paris-Soir, 16. Juli.

156 Zit. bei du Réau, Daladier, S. $322 \mathrm{f}$.

157 La Lumière, 14. Juli; Ce Soir, 15. Juli.

158 In Daladiers Kommuniqué vom 15. Juli hieß es verbrämt, die unlängst festgenommenen Personen seien "mit Agenten einer ausländischen Macht in Kontakt getreten“ und hätten "bedeutende Geldsummen" empfangen.

159 Paris-Soir, 15. Juli; Match, 20. Juli; L'Epoque, 25. Juli. Vgl. du Réau, Daladier, S. $319 \mathrm{ff} . ;$ nach ihrer Darstellung bestärkte der Fall Aubin-Poirier Daladier in seinem Entschluß, Nachrichtenwesen und Rundfunk unter staatliche Kontrolle zu stellen. Zwei am 29. Juli erlassene Dekrete schufen hierzu ein „Commissariat général à l'information" unter Leitung des Schriftstellers Jean Giraudoux. Bonnet hatte vergeblich Jules Romains favorisiert. 
affäre in Verbindung gebracht", vermerkte das Auswärtige Amt ${ }^{160}$. Botschafter Welczeck beklagte, daß diese Verquickung von amtlicher französischer Seite "unwidersprochen“ bleibe. Mit dem Fall Aubin-Poirier sei „jeder Bann gebrochen und die bisherige Zurückhaltung in der Presse einem hemmungslosen, nur noch als hysterisch zu bezeichnenden Wüten über die deutsche Spionage in Frankreich gewichen". Selbst Zeitungen, „die bisher trotz aller grundsätzlichen Gegnerschaft zu Deutschland [...] ein gewisses Niveau wahrten, wie z. B. Petit Parisien", beteiligten sich mittlerweile an diesem „Feldzug“. Der Botschafter witterte ein auch von englischer Seite inspiriertes ,konzentrisches Vorgehen aller deutschfeindlichen Kräfte" und interpretierte das Geschehen dahingehend, daß es sich „nicht nur um den Fall Abetz selbst, sondern um das größere Ziel der Störung der deutsch-französischen Beziehungen" handele. Nicht zuletzt sei die Absicht erkennbar, Bonnet zu stürzen; man versuche, ihn über seine Frau zu diskreditieren, der Botendienste zwischen ihrem Gemahl und den Deutschen unterstellt wür$\operatorname{den}^{161}$.

Die „vom Fall Abetz ausgehende Deutschenhetze“ schlug auch auf Angehörige der Pariser Botschaft durch, wie Welczeck am 21. Juli berichtete. Mehrere Zeitungen warfen Gesandtschaftsrat Dr. Ehrich und Konsulatssekretär Geiger unter Hinweis auf ihre Tätigkeit in der NS-Auslandsorganisation vor, ihren Status zum Zweck unerlaubter Propaganda zu mißbrauchen ${ }^{162}$. Am 19. Juli behaupteten L'Ordre und L'CEuvre, der im März nach Berlin zurückberufene Gesandtschaftsrat Bräutigam habe im Schutze diplomatischer Immunität zusammen mit Abetz, Bran und anderen frankreichfeindliche Propaganda getrieben. Er sei wegen seiner zu exponierten Stellung aus Frankreich abgezogen worden. In der Reichshauptstadt soll Bräutigam dann eine 120 Seiten starke Denkschrift mit dem Titel „Die Ansatzpunkte an der inneren Widerstandskraft Frankreichs" verfaßt haben, basierend auf seinen Erfahrungen während der Septemberkrise 1938. Das Memorandum diene den zuständigen Reichsstellen als Leitfaden und habe sie bewogen, den Etat für Auslandspropaganda aufzustocken ${ }^{163}$. Die beiden Zeitungsberichte erscheinen typisch für jene Mischung aus Tatsachen, Halbwahrheiten und Sensationseffekten, die gerade in spannungsreichen Phasen Konjunktur hat und zum vorsichtigen Gebrauch der Quellen mahnt. Da wird von einer verschworenen Troika Abetz-Bran-Bräutigam seit gemeinsamen Karlsruher Jugendzeiten er-

160 Aufzeichnung vom 19. Juli; PA/AA, R 29586.

161 Welczeck an Auswärtiges Amt, 15. 7. 1939; PA/AA, Botschaft Paris 1156c. Abetz bestritt, vor dem Krieg Geld verteilt, geschweige Aubin und Poirier gekannt zu haben. Protokoll der Sûreté Nationale Nr. 204/5 vom 26. 11. 1945, „Déclarations relatives à la mesure d'expulsion prise à son encontre en 1939“; AN, F 7/15331. Die zitierte AA-Aufzeichnung vom 19. 7. 1939 vermerkt, der „Pressesturm“ habe sich seit Veröffentlichung der Dala-

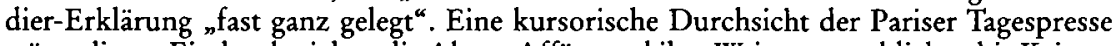
stützt diesen Eindruck nicht - die Abetz-Affäre und ihre Weiterungen blieben bis Kriegsausbruch ein unvermindert heißes Thema, das mit Abetz' Bemühungen, einen Prozeß gegen Kerillis anzustrengen, neuen Zündstoff erhielt.

162 L'Epoque, 9. Juli; Messidor, 14. Juli; Regards, 20. Juli.

163 Welczeck an Auswärtiges Amt, 21.7. 1939; PA/AA, R 101322. Beigefügt ist eine Kopie des Ordre-Artikels, der laut Welczeck auf einer Meldung der Agence radicale indépendante von Anfang Mai fußte. 
zählt, für die sich im Lebenslauf Bräutigams jedoch kein Anhaltspunkt findet. Geboren 1895 in Wesel und aufgewachsen im westfälischen Coesfeld, bekleidete der Wirtschaftsexperte nach Studien in Grenoble, Oxford, Straßburg und Münster in den zwanziger Jahren diplomatische Posten in Tiflis, Baku, Charkow, Odessa und Moskau. Von 1930 bis 1935 war er im Wirtschaftsreferat Sowjetunion des Auswärtigen Amtes tätig, von Januar 1936 bis März 1939 Leiter der Konsulatsabteilung an der Pariser Botschaft - frühestens hier dürfte er in engeren Kontakt zu Abetz gekommen sein. Eine Denkschrift mit dem genannten Titel und Inhalt ließ sich im Fundus des Auswärtigen Amtes nicht ermitteln ${ }^{164}$.

Aus der üblichen Presseberichterstattung zum Fall Abetz, die zuweilen etwas hysterisch anmutet und die allenthalben tiefe Verunsicherung über das Ausmaß nationalsozialistischer Umtriebe in Frankreich spiegelt, ragen einige Beiträge heraus, deren Verfasser offensichtlich um eine differenzierte Beurteilung des Deutschen bemüht waren. Sie zeigen einmal mehr die Schwierigkeiten schon der Mitlebenden, den schillernden Charakter und zwiespältigen Werdegang von Abetz zu begreifen. Daß sie in einem so krisenhaften Moment publiziert wurden, mag je nach Standpunkt belegen, wie überzeugend sein Verständigungsstreben geraume Zeit gewirkt haben muß - oder wie erfolgreich er, seine wirklichen Absichten verbergend, an der Legende des wahren Frankreichfreundes strickte. Keiner der Autoren kam indessen umhin, einen Bruch, einen Persönlichkeitswandel hin zur Doppelzüngigkeit zu konstatieren.

Eine psychologisch einfühlsame Reportage in Match, die Sohlberg-Ära als idealistischen Ausgangspunkt skizzierend, sah Abetz 1933 in der klassischen Situation des La Fontaineschen Schilfrohrs: „Il faut plier ou être rompu.“ Zurück in Paris, habe er seine Zustimmung zum NS-Regime keineswegs verleugnet und erfolgreich zu vermitteln gewußt, daß die Gelegenheit zur Aussöhnung günstig sei: „Il triomphe d'autant plus allègrement qu'il est sincère et qu'il croit à la sincérité de son Führer." Doch der Aufrichtigkeitsanspruch verkam spätestens nach ,München' zum Roßtäuschertrick: „S'il continue de le servir, il ne fait plus de convertis, il fait des dupes. Il était loyal, il ment. Sa sincérité devient un métier [...] Un sale métier." Längst war es zu spät, zurückzuziehen: „reculer, c'est tomber dans un gouffre. Très bas, et de très haut.“ Am Ende dieser Entwicklung, resümierte Match, stehe ein „verdorbener Idealist“, der nicht spioniere, wohl aber sondiere, irreführe, zu überreden suche, mit viel Gespür für die Schwäche seines jeweiligen Gegenübers: Käuflichkeit, Eitelkeit, Gefühlsduselei, Naivität165. Die Zeitung L'Ordre prangerte seine "skandalösen Aktivitäten“ an ${ }^{166}$, stellte aber zugleich fest, daß Abetz nach der nationalsozialistischen ,Machtergreifung' nicht zu jenen gehörte, die von heute auf morgen die Farbe wechseln: "Lentement, et comme à regret, M. Abetz se persuadait de la grandeur du nazisme." Gerade diese augenscheinliche Mäßigung habe das Mißtrauen bei alten Freunden der Linken eingeschläfert - ein Konvertit sei schließlich kein Abtrünniger. „La propagande hitlé-

164 Schriftl. Mitteilung an den Verf. vom 3.6. 1993 mit einem tabellarischen Lebenslauf Otto Bräutigams.

165 "Otto Abetz, l'idéaliste corrompu et content", unsig.; Match, 20. 7. 1939.

166 L'Ordre, 3. Juli. 
rienne sut tirer parti de la nuance. "167 Der Publizist und Deutschlandexperte Edouard Lavergne, mit Abetz bekannt, nannte dessen frühere Lehrertätigkeit, in pointierter Abgrenzung zur späteren Laufbahn, eine „erste Fleischwerdung“. In einem Beitrag für den Petit Parisien porträtierte er den Badener als glänzenden Verwandlungskünstler und zuweilen miesen Heuchler - „il joua la naïveté avec une apparence de sincérité qui était humiliante" -, der beim Anschluß an die $\mathrm{Ha}$ kenkreuzpartei enorme Wendigkeit bewiesen habe, eine Geschmeidigkeit, die ihm gesprächsweise fehle. Nun bemühe er sich, eine Rolle zu spielen, die ihm schlecht anstehe, und flüchte sich in Zynismus. Dabei hege er im Grunde seines Herzens Bewunderung für den französischen Geist. Betrübliche Folge dieser Unstimmigkeit: „La blague et le paradoxe, dans sa bouche, font l'effet d'un vin de Bordeaux que l'on boirait dans un pot de bière." Eine Gefahr erblickte Lavergne darin, daß Abetz in Paris häufig mit Naivlingen, Extremisten und NS-Symphatisanten verkehrt habe, deren vom nationalen Wollen abweichende Ansichten die Berliner Führung verleiten könnten, die französische Entschlossenheit zur Gegenwehr zu unterschätzen ${ }^{168}$. Der Marineoffizier, Journalist und spätere prominente Widerständler Emmanuel d'Astier de La Vigerie, der Abetz auf dem Nürnberger Parteitag 1936 kennenlernte, diagnostizierte ebenfalls einen wachsenden Hang zur Unehrlichkeit. Abetz ließ sich nach seinem Urteil zu sehr mit dem Nationalsozialismus ein, als daß er es hätte vermeiden können, eines Tages seine Überzeugungen zu verraten. Die Schwierigkeiten, denen er 1937 in Deutschland ausgesetzt war ein Hinweis auf die Intrige der Reichsstudentenführung -, seien wohl der Auslöser gewesen, Hitlers Spiel in Frankreich mit größerer Konsequenz und Unverfrorenheit zu betreiben als zuvor ${ }^{169}$.

\section{6. „Keine Regierung kann eine solche Propaganda dulden“: Vergebliche Rehabilitierungsversuche}

Durch das Eingreifen Ribbentrops gewann die Affäre abermals eine neue Dimension. Kaum hatte sich die Aufregung um Danzig etwas gelegt, kündigte er energische Schritte an, um „eine alsbaldige Wiederzulassung von Herrn Abetz herbeizuführen“. Listig versuchte der Reichsaußenminister den fatalen Eindruck zu mildern, den das Verhalten des „Freundes und langjährigen Mitarbeiters“ hinterlassen hatte, indem er auf dessen schwer widerlegbaren persönlichen Verständigungswillen abhob und seine seit Jahren im institutionellen Rahmen der ,Dienststelle verankerten Initiativen zum rein "privaten Verständigungswerk" erklärte. Welczeck sollte Daladier nachdrücklich darauf hinweisen, daß Abetz sich stets „in völlig selbstloser Weise als Privatmann" (!) um einen Ausgleich bemüht und in schwierigen Lagen dazu beigetragen habe, die wechselseitigen Beziehungen „in

167 „L'homme du jour: Herr Abetz ; L'Ordre, 8. Juli.

168 Edouard Lavergne, J'ai connu Otto Abetz, in: Le Petit Parisien, 28. Juli. Enthält die sonst nirgendwo aufgestellte Behauptung, Suzanne Abetz sei „überzeugte Nationalsozialistin“.

169 Emmanuel d'Astier, Mon ami Otto Abetz, in: Marianne, 26. Juli. 
ruhige Bahnen zu lenken“. Die deutsch-französische Freundschaft sei „sein Lebensziel“, die für seinen Ausschluß aus Frankreich genannte Begründung „eine ganz gesuchte und widersinnige" 170 .

Zwei Gründe erscheinen ausschlaggebend für Ribbentrops Zorn. Es mußte ihn schmerzen, einen für die psychologische Kriegführung überaus wertvollen Mann nicht länger vor Ort einsetzen zu können ${ }^{171}$. Darüber hinaus litt seine eigene Glaubwürdigkeit noch stärker als ohnehin, solange Abetz nicht rehabilitiert war. Einen solchen Prestigeverlust aber wollte er nicht hinnehmen, zumal er gerade auf anderem Feld einen erbitterten Meinungsstreit mit Bonnet ausfocht. Hierbei ging es um die Frage, ob die französische Regierung anläßlich der Unterzeichnung der Freundschaftserklärung am 6. Dezember 1938 ein generelles Desinteresse an osteuropäischen Entwicklungen bekundet habe ${ }^{172}$. Während Ribbentrop Bonnets damalige Äußerungen dementsprechend interpretierte ${ }^{173}$ und den Osten unverblümt zur exklusiven Einflußzone des Reiches erklärte, bestritt letzterer ein derartiges Entgegenkommen ${ }^{174}$. Paris habe allenfalls ein wirtschaftliches Übergewicht Deutschlands in Mitteleuropa akzeptiert, bekräftigte er am 1. Juli 1939 gegenüber Welczeck. Eine Politik der freien Hand in den jeweiligen Interessensphären könne jedoch nicht bedeuten, daß man manu militari Teile des Nachbarlandes einfach unterwerfe ${ }^{175}$. Ribbentrop konterte, die Reichsregierung verbitte sich „ein für allemal" Einmischungen in "ureigenste" Angelegenheiten. Hinsichtlich der jüngsten Entwicklung hieß das: keine Erörterung der deutsch-polnischen Beziehungen mit Frankreich und schon gar nicht "das Recht zu einer Einflußnahme auf Fragen [...], die mit der künftigen Gestaltung des Schicksals der deutschen Stadt Danzig zusammenhängen" 176 .

In Anbetracht dieser Polarisierung verwundert nicht, daß beide Seiten auch die Abetz-Affäre als Prestigesache behandelten. Als Botschafter Graf Welczeck am

170 Ribbentrop an Botschaft Paris, 9. 7. 1939; ADAP, D VI, Nr. 640.

171 Kerillis hat diesen Aspekt klar erkannt: „De toute évidence, l'absence d'Abetz [...] est gravement ressentie par la diplomatie allemande [...] Il se trouve loin de France au moment où son action serait plus utile que jamais!“ L'Epoque, 15. 8. 1939.

172 Zur Genese dieser Kontroverse DDF, 2, XIII, Nr. 58; ADAP, D IV, Nr. 370; ausführlich Bellstedt, „Apaisement" oder Krieg, S. 43-49; Duroselle, La décadence, S. $387 \mathrm{ff}$.

173 Unter anderem in einer Unterredung mit Coulondre am 7. 2. 1939; ADAP, D IV, Nr. 383.

174 Zur Unhaltbarkeit der Ribbentropschen Position Knipping, Deutsch-französische Erklärung, S. 547ff. Kritik am insgesamt zu unverbindlichen Kurs Bonnets übt Adamthwaite, France, Kap. XV, bes. S. 278: „The distinctive trait of French diplomacy in the six months from Munich to Prague was ambiguity". Tatsächlich sah sich Bonnet schon unmittelbar nach dem 6. Dezember zu einem Dementi im Parlament veranlaßt: „l'accord ne laisse nullement, comme on l'a dit parfois, à l'Allemagne des mains libres à l'Est.“ - „Exposé du ministre à la Commission des affaires étrangères de la chambre du 6 décembre 1938 sur l'Allemagne“; MAE, Papiers 1940, Cabinet Bonnet/1. Welczeck sagte er im Hinblick auf eine anstehende Parlamentsrede, manche Passagen seien ,für den inneren Gebrauch abgefaßt [...] Hierbei erwähnte er das absolute Festhalten an der französischen Politik im östlichen Europa."Welczeck an Auswärtiges Amt, 24.1. 1939; ADAP, D IV, Nr. 380.

175 Bericht Welczecks; ADAP, D VI, Nr. 603. Aufzeichnung Bonnets vom 1. 7. 1939; DDF, 2, XVII, Nr. 67.

176 Ribbentrop an Bonnet, 13. 7. 1939; ADAP, D VI, Nr. 669, Anlage. 
11. Juli bei Daladier vorsprach und weisungsgemäß argumentierte, Abetz, ein verdienter Vorkämpfer der deutsch-französischen Verständigung, sei über jeden Zweifel erhaben und infam verleumdet worden, blitzte er rundweg ab. Auf seine wortreiche Beschwerde über eine „konzentrisch von unseren Gegnern systematisch betriebene Hetze“, wofür der Fall Abetz geradezu ein Schulbeispiel sei, entgegnete der Regierungschef lakonisch, daß bestimmte Worte und Handlungen in einer günstigen Atmosphäre eben anders wirkten und beurteilt würden als in Krisenzeiten. Aufgrund übereinstimmender Informationen und telefonischer Kontrollen sei der "Eindruck alarmistischer Nachrichtenverbreitung" entstanden, was er nicht dulden könne. Nur vage stellte er eine Überprüfung in Aussicht, ob und inwieweit Mißverständnisse vorlägen. Welczecks Einwurf, der Zwischenfall strapaziere unnötig die bilateralen Beziehungen, parierte Daladier mit der Bemerkung, das Vertrauen in Hitler sei ohnehin „schwer erschüttert“. Die Franzosen fühlten sich "durch unseren dem Wort und dem Geist des Münchener Abkommens widersprechenden Willkürakt" - die Unterwerfung der Tschechei - "getäuscht" und "ridikülisiert". Welczeck hatte wenig entgegenzusetzen und resümierte einigermaßen ratlos: „Einfach denkend, oft etwas stur, ist Daladier, einmal in eine Idee verrannt, schwer zu überzeugen, ganz besonders aber, wenn persönlich verärgert. “ 177

Damit gab sich Ribbentrop natürlich nicht zufrieden. Er drängte zu „frontalem Vorgehen “, da Paris den Fall Abetz offenbar verschleppen wolle. Sichtlich bemüht, eine Nagelprobe herbeizuführen, kündigte er die Wiedereinreise seines verbannten Mitarbeiters nach Frankreich "in den nächsten Tagen “ ${ }^{178}{ }^{17}$. Welczeck wollte eigentlich lieber bei Bonnet nachfassen, bei dem er mit guten Gründen mehr Nachgiebigkeit erwarten durfte, doch der Reichsaußenminister bestand auf einer zweiten Demarche bei Daladier ${ }^{179}$. In dessen Amtszimmer sprach Welczeck am 20. Juli erneut vor, wiederholte seine Argumente ,in energischster und dringlichster Form" und verlangte, daß wenigstens „die ehrabschneiderische Pressehetze gegen Herrn Abetz mit allen Mitteln unterbunden" werde. Daladier rückte keinen Deut von den erhobenen Vorwürfen ab: Es stehe fest, daß Abetz „in alarmistischer Form" eine baldige Aktion gegen Danzig angekündigt und "durch seine Geschäftigkeit propagandistische Absichten" verraten habe. Im übrigen versuchte der Ministerpräsident den deutschen Protesten die Spitze zu nehmen, indem er hervorhob, der Ausweisungsbefehl sei ja gar nicht zugestellt worden, man habe Abetz nur höflich gebeten, das Land zu verlassen. Daraufhin behauptete Welczeck weisungsgemäß, Abetz halte sich seines Wissens in Südfrankreich auf, „was Daladier zu einem Ausruf stärksten Erstaunens veranlaßte. Seinem Versuch, gegen die Wiedereinreise aufzubegehren, begegnete ich mit dem Hinweis

177 Welczeck an Auswärtiges Amt, 12. 7. 1939, ebenda, Nr. 658. In einem 1949 vor Gericht verlesenen Brief bekräftigte Daladier, "des informations nombreuses et précises“ hätten Abetz' propagandistische Umtriebe, zuletzt in Vorbereitung der deutschen Aggression gegen Polen, dokumentiert. Protokoll vom 16. 7. 1949, pag. 95f.; AN, 334 AP 49.

178 Weizsäcker an Botschaft Paris, 13. Juli; ADAP, D VI, Nr. 664.

179 Welczeck an Auswärtiges Amt, 14. Juli; Weizsäcker an Botschaft Paris, 16. Juli; PA/AA, R 29586. 
auf seine eigene Feststellung, daß eine gültige Ausweisung ja nicht vorliege."180 Man beharkte einander mit diplomatischen Winkelzügen. Abetz hielt sich zum fraglichen Zeitpunkt mitnichten in Frankreich auf, sondern urlaubte mit seiner Familie in einem Ostseebad ${ }^{181}$. Anderslautende Meldungen waren eine kühl kalkulierte Finte, um die Pariser Regierung unter Druck zu setzen und die Affäre am Kochen zu halten ${ }^{182}$. Daladier hätte sich gern hinter der Tatsache verschanzt, daß Abetz, obschon ein Ausweisungsbefehl existierte, „freiwillig“ abgereist und somit eine formelle Vollstreckung der Order unterblieben war. Genau an diesem Punkt hakte das Auswärtige Amt ein und bestritt die rechtliche Grundlage, Ribbentrops Referenten zur unerwünschten Person zu erklären. Das gesteckte Ziel, ihn fernzuhalten, erreichte die französische Regierung trotzdem mühelos, indem sie ihm bei nächster Gelegenheit einfach die Wiedereinreise verwehrte - so geschehen Anfang August, als Abetz am Grenzübergang Basel abgewiesen wurde ${ }^{183}$. Er wollte, getarnt durch einen Umweg über die Schweiz, nach Paris fahren, um „zur Rettung seiner Ehre" einen Verleumdungsprozeß gegen de Kerillis anzustrengen. Staatssekretär v. Weizsäcker instruierte Welczeck, behilflich zu sein und dem Kläger „als Privatperson in der Botschaft Wohnung zu geben" 184.

Hitler hatte persönlich die Einleitung juristischer Schritte gebilligt. Ende Juli bestellte er Abetz und den in französischer Jurisdiktion bewanderten Friedrich Grimm nach Bayreuth, wo er heiter gestimmt als Gast Cosima Wagners die Festspiele genoß. Abetz hatte seinen DFG-Kollegen über Einzelheiten ins Bild gesetzt und behauptet, die "Hetze gegen unsere Freunde in Paris" sei so unerträglich geworden, daß sie ihn um ihrer eigenen Entlastung willen gebeten hätten, Anzeige zu erstatten ${ }^{185}$. Hitlers fadenscheinige Frage, ob er auch wirklich nie eines der ihm von seinen Feinden zur Last gelegten Vergehen begangen habe, verneinte er. „Solche Dinge wie Spionage gibt es leider", erwiderte Hitler gleichgültig. „Sie sind nicht schön, aber auch wir kommen nicht darum herum" 186 . Er hielt es für wenig opportun, ein Verfahren anzustrengen, denn bei solchen Beleidigungsprozessen komme ja doch nichts heraus: „Ich habe mit dieser Form demokratischer Justiz

180 Welczeck an Auswärtiges Amt, 20. Juli; ADAP, D VI, Nr. 690.

181 Friedrich Grimm, „Die Affäre Abetz“, in: Lebenserinnerungen eines deutschen Rechtsanwalts (Manuskript), VI, pag. 338f.; BA Koblenz, Nachl. Grimm/14.

182 Vgl. Aussage Feihl, Protokoll Nr. 149/2 der Sûreté Nationale vom 1. 9. 1946. Brief Feihls an Welczeck vom 30. 9. 1946 (Auszug in französischer Übersetzung): Er habe bei seiner Vernehmung in Paris berichtet „sur les instructions mensongères selon lesquelles Abetz se serait à nouveau trouvé en France à l'époque“. AN, 3 W 358, Dossier Feihl.

183 Weizsäcker an Botschaft Paris, 4. 8. 1939; ADAP, D VI, Nr. 767. Ein „hinterhältiges“ Manöver, wie der Botschafter befand. Welczeck an Auswärtiges Amt, 7. August; PA/AA, R 29586.

184 Weizsäcker an Botschaft Paris, 2. August; ADAP, D VI, Nr. 755. In diesem Telegramm heißt es, daß Abetz ,bereits in Frankreich ist und in den nächsten Tagen sich in Paris einfinden wird", womit Weizsäcker entweder bewußt eine Fiktion aufrechterhielt oder voreilig davon ausging, die Einreise werde gelingen.

185 Grimm, „Die Affäre Abetz“, pag. 339 f.

186 Zit. bei Abetz, Das offene Problem, S. 107. Eine verkürzte Version gab er den Nürnberger Anklagebehörden am 25. 8. 1946 zu Protokoll. „Les motifs de ma nomination comme ambassadeur à Paris"; CDJC, LXXI-111. 
schlechte Erfahrungen gemacht. Da bleibt dann immer etwas hängen [...], da in der Presse alles entstellt dargestellt wird. " 187 Friedrich Grimm hingegen riet dringend zur Klage - das sei man den französischen Freunden einfach schuldig. Über das Procedere hatte er sich schon eingehend Gedanken gemacht, entwickelte nun seine Strategie, wobei er hervorhob, daß man das Verfahren nach Belieben verschleppen könne. Indem man sich auf de Kerillis konzentriere, der „am lautesten geschrien“ habe, jage man zugleich allen anderen Schreiberlingen „einen heillosen Schrecken“ ein. Abetz müsse seine Anzeige „sehr energisch begründen“ und eine Geldstrafe von mindestens einer Million Francs verlangen. Journalisten vom Schlage eines Kerillis seien meist feige und geizig und die Zeitungen nicht geneigt, ihre Schriftleiter bei derartigen Schadenersatzansprüchen schadlos zu halten.

Diese Marschroute schien Hitler zu überzeugen; er revidierte seine Meinung und gab grünes Licht für einen Prozeß. Auch Ribbentrop stimmte ausdrücklich zu. Anfang August, nach einer effektheischenden Pressekonferenz in Berlin, reichte Abetz bei den Pariser Justizbehörden eine von Grimm formulierte Klageschrift ein. Sie richtete sich vor allem gegen de Kerillis' Behauptung, er sei ein Mittelsmann bei der Finanzierung nationalsozialistischer Propaganda in Frankreich gewesen ${ }^{188}$. Sodann hielt Grimm in Paris Ausschau nach einem geeigneten Anwalt. Besondere Eile sei nicht geboten, meldete er Mitte August, da „alle in $\mathrm{Fe}-$ rien “. Als Wunschkandidaten, der Abetz' Klage vertreten sollte, benannte er Jean Montigny. Der rechte Kammerabgeordnete, Renegat aus der Radikalsozialistischen Partei, hatte in den zwanziger Jahren gemeinsam mit Luchaire, Emile Roche, Jacques Kayser, Robert Lange und anderen zu den „Jeunes Turcs" gehört. Er saß geraume Zeit im Ehrenpräsidium des Comité France-Allemagne und schrieb seit 1938 Kolumnen für Notre Temps. Als entschiedener Kriegsgegner hatte er soeben mit 14 anderen Parlamentariern ein "Comité de liaison contre la guerre" gegründet. „Es wäre sehr glücklich, wenn er akzeptierte“, schrieb Grimm. "Ist sowohl politisch wie auch als Anwalt sehr angesehen." ${ }^{189}$

Zufrieden vermerkte die Wilhelmstraße, Abetz' Klage mache die „französischen Kriegsschürer nervös“. Neue Geschichten würden verbreitet, um eine Stimmung zu erzeugen, die eine Rückkehr des Deutschen nach Paris zur Wahrnehmung seiner Interessen vereiteln solle ${ }^{190}$. Henri de Kerillis mäßigte sich mitnichten, sondern quittierte die Entwicklung mit beißendem Spott: Der „gewesene Großmeister Hitlerscher Propaganda und Bestechung" wolle den Franzosen

187 Zit. bei Grimm, „Die Affäre Abetz“, pag. 340; nach seinen Erinnerungen auch das Folgende.

188 Vgl. L'Epoque, 3. 8. 1939.

189 Grimm (Paris) an Abetz (Berlin), 19. 8. 1939; Vermerk Grimm, „Betrifft: Prozeß Abetz“, vom selben Tag; PA/AA, Personalakte Abetz/1. Grimm favorisierte auch Gaston Bergery: „ist politisch abgestempelt, aber mutig und zuverlässig und würde als Gegenstück zu Paul-Boncour [Anwalt von Kerillis] eine sehr glückliche Wahl bedeuten ". In Abetz' Memoiren heißt es, Rechtsanwalt Maurice Garçon von der Academie française habe sich bereit erklärt, ihn juristisch zu vertreten; Das offene Problem, S. 106. Grimm kannte Garçon seit 1926, als letzterer einen Leutnant der französischen Besatzungstruppen verteidigte, der des Totschlags an einem Bürger von Germersheim angeklagt war. Grimm, Mit offenem Visier, S. $100 \mathrm{ff}$.

190 Auswärtiges Amt an Botschaft Paris, 9. 8. 1939; PA/AA, Botschaft Paris 1270. 
weismachen, daß er nur ein unschuldiger Tourist sei, begeistert von schönen Landschaften und gepflegter Konversation ${ }^{191}$. Hohntriefend regte er die Gründung einer "Vereinigung Epoque-geschädigter Hitlerfreunde“ an und wähnte ein Kesseltreiben gegen sich im Gang, als nun auch der Pariser Stadtrat Darquier de Pellepoix, aggressiver Antisemit und künttiger Judenkommissar Vichys, und Fernand de Brinon Strafanzeige stellten. Brinon, von de Kerillis regelmäßig als intimer Freund und serviler Informant Ribbentrops abqualifiziert, hatte schon nach seiner umstrittenen Berlinvisite im Februar mit gerichtlichen Schritten gedroht. Jetzt forderte er - Zufall oder nicht - ebenfalls eine Million Francs Schadenersatz, und der Beklagte glaubte zu wissen warum: „Brinon marche parce qu'on lui a dit de marcher, comme Abetz [...] Les deux hommes sont poussés comme deux pions sur l'échiquier par von Ribbentrop." 192

Die Ausweisungsaffäre schwelte unterdessen weiter. Nachdem Abetz die Rückkehr nach Frankreich verweigert worden war, intervenierte Botschafter Welczeck am 8. August bei Bonnet, der „ernstlich bemüht" schien, einen Ausweg zu finden, gleichwohl die "Schwierigkeiten einer befriedigenden Regelung wegen innerpolitischer Gründe nicht verhehlte "193. Am 10. August empfing er Welczeck erneut und bekundete seine Absicht, Daladier eine „eindeutige Ehrenerklärung“ für Abetz vorzuschlagen, um weiteren Angriffen in der Presse vorzubeugen. $\mathrm{Zu}$ gleich aber betonte Bonnet, daß die Vorwürfe von amtlicher Seite in vollem Umfang bestehenblieben. Abetz habe zweifelsfrei versucht, die französische Entschlossenheit zu lähmen - keine Regierung könne in politisch so gespannten Zeiten eine defätistisch wirkende Propaganda wie diese dulden. Der Deutsche sei zur Zeit „unerwünscht“, eine Wiedereinreise komme frühestens in einigen Wochen in Betracht, wenn sich die Wogen geglättet hätten. Coulondre, gerade in Paris zugange, äußerte sich in ähnlichem Sinn und bat zu bedenken, daß Abetz' Einreise zum gegenwärtigen Zeitpunkt "die Regierung in Gefahr bringen würde"194.

Recht deutlich lassen diese Stellungnahmen die Beweggründe der Pariser Regierung und die Tragweite, die sie der Affäre beimaß, durchscheinen. Man hatte endlich begriffen, daß Hitler die französische Staatsautorität von innen her zu schwächen suchte, und wurde für augenfällige Versäumnisse bei der Abwehr dieser Gefahr von Teilen der Presse heftig kritisiert. Folglich mußte Daladier daran liegen, den eine Politik der Stärke konterkarierenden Abetz loszuwerden. Nicht völlig auszuschließen ist, daß der Ausweisungsbefehl vom 30. Juni die Wirkung der

191 „L'espion Abetz poursuit Henri de Kerillis!" L'Epoque, 3. August.

192 „Ribbentrop déclenche Brinon“; L'Epoque, 11. August. In einem Brief an seinen Anwalt Paul-Boncour vom 6. November 1939 schwächte de Kerillis die Vorwürfe gegen Brinon $\mathrm{ab}$, beharrte aber darauf, daß dessen Aktivitäten zum Ziel gehabt hätten, die Aufmerksamkeit seiner Landsleute von Hitlers Planungen abzulenken. Das mindeste, was man zum Comité France-Allemagne sagen könne, sei, daß es die Franzosen niemals über die deutsche Gefahr aufgeklärt, sondern stets auf eine Weise informiert habe, die auf eine Komplizenschaft mit der NS-Propaganda schließen lasse. AN, 411 AP 1, dr. 6.

193 Welczeck an Auswärtiges Amt, 8. 8. 1939; PA/AA, R 29586.

194 Welczeck an Auswärtiges Amt, 11. August; ADAP, D VII, Nr. 22. Im Original ist das letzte Zitat unterstrichen. Abetz zitiert das Dokument in seinen Erinnerungen, allerdings in ausformulierten Sätzen anstelle des ursprünglichen Telegrammstils; Das offene Problem, S. $105 \mathrm{f}$. 
Bonnet-Note vom 1. Juli erhöhen und die französische Festigkeit nochmals unmißverständlich zum Ausdruck bringen sollte. Dagegen spricht allerdings das erkennbare Bemühen Bonnets, kein Öl ins Feuer zu gießen und den Dialog mit Ribbentrop nach Möglichkeit aufrechtzuerhalten. Der Reichsaußenminister hatte Mitte Juli seine jüngste Korrespondenz mit den Franzosen veröffentlicht. Obwohl Bonnet, der diese Briefe als vertraulich einstufte, darüber verärgert war ${ }^{195}$, erläuterte er am 21. Juli in einem langen, höflichen, an Ribbentrop persönlich adressierten Schreiben noch einmal geduldig den französischen Standpunkt bezüglich einer militärischen Hilfeleistung für Polen ${ }^{196}$. Bezeichnenderweise war von seiner Seite auch nie von Spionage die Rede, diesen Vorwurf gegen Abetz erhob ausschließlich die Presse. Den Wunsch, die Tür nach Deutschland angelehnt zu lassen, dokumentiert schließlich jene Ehrenerklärung, zu der sich Daladier nach einigem Zögern durchrang. Der regierungsamtliche Text, am 14. August in den Pariser Morgenzeitungen abgedruckt, stellte aus französischer Sicht eine moralische Satisfaktion und Kompromißformel dar: Abetz wurde ausdrücklich vom Verdacht der Spionage reingewaschen, seine Anwesenheit in Frankreich aber nach wie vor für unerwünscht erklärt ${ }^{197}$. Wie abzusehen, reichte dies nicht aus, Berlin zufriedenzustellen. Botschaftsrat Bräuer mäkelte sogleich, das Kommuniqué „könne uns nicht genügen “, während Staatssekretär v. Weizsäcker Coulondre beschied, damit sei der Fall "nicht in Ordnung "198.

Bonnet zufolge ${ }^{199}$ wollte die französische Regierung mit der Erklärung vor allem Graf Welczeck einen Dienst erweisen. Der Botschafter soll am 8. August unter vier Augen eingeräumt haben, auf Kriegsfuß mit Abetz zu stehen, der ihn im Auftrag Ribbentrops überwache. In Berlin kursierten gar Gerüchte, wonach er, Welczeck, mitverantwortlich für die Abschiebung sei. Hitler und Ribbentrop hätten ihn vor die Wahl gestellt, Abetz die Rückkehr nach Paris zu ermöglichen oder seines Postens enthoben zu werden. Diese Eröffnung, so Bonnet, habe ihn sehr beunruhigt. Daladier und er seien sich einig gewesen, alles zu tun, um Welczeck zu stützen, der als besonnen galt und dessen Anwesenheit in Paris gerade in jenen kritischen Wochen, da „ein Klima wie vor München" 200 herrschte, von unschätzbarem Wert sein konnte. Vor einem parlamentarischen Untersuchungsausschuß bekräftigte Bonnet 1951, daß Welczeck und Abetz einander nicht grün gewesen seien - für ihn logische Folge einer Kluft zwischen einem Diplomaten alten Schlages, "qui ne jouit pas de la confiance de Ribbentrop“, und einer Handvoll halbamtlicher Dienste, die sich respektlos in die auswärtigen Beziehungen einmischten. „Et M. Abetz était un des plus beaux fleurons de ces sortes de missions officieuses", pflichtete ihm der Abgeordnete Charles Serre bei201.

195 Campbell an Halifax, 19. 7. 1939; DBFP, 3, VI, Nr. 359.

196 Abgedruckt in: Livre Jaune. Documents diplomatiques 1938-1939, Nr. 168.

197 Abgedruckt in: Bräuer an Auswärtiges Amt, 14. 8. 1939; ADAP, D VII, Nr. 49.

198 Aufzeichnung v. Rintelen, 14. August; PA/AA, R 29586. Aktenvermerk v. Weizsäcker, 15. August; ADAP, D VII, Nr. 65.

199 Bonnet, Dans la tourmente, S. $158 \mathrm{ff}$.

200 Saint-Hardouin (Berlin) an Bonnet, 12. 8. 1939; Livre Jaune, Nr. 191.

201 AN-Enquête, IX, S. 2610, 2629; dort auch das Urteil Blums über Welczeck aus dem Jahr 1936: „un ambassadeur qui observe la France avec impartialité, intelligence et sympathie“. 
Nicht allein die häufig unzuverlässigen Überlieferungen Bonnets erlauben die Frage, ob Welczeck, seine Reputation gezielt in die Waagschale werfend, mit seinem Bekenntnis nur ein zusätzliches Druckmittel schaffen wollte. Anläßlich der ersten Demarche bei Daladier am 11. Juli war er immerhin bereit, „persönlich jede Garantie" für Abetz zu übernehmen ${ }^{202}$. Französische Zeitungsberichte, die ein Zerwürfnis, ein Gegeneinander-Arbeiten der beiden unterstellten, dementierte er mit großer Entschiedenheit. „Wie ich schon dem Herrn Reichsaußenminister persönlich vorgetragen habe, besteht zwischen Herrn Abetz und mir eine Atmosphäre völligen Vertrauens und absoluter Loyalität", telegraphierte er nach Berlin. "Ich habe auch Herrn Daladier keinen Zweifel darüber gelassen, daß es nur eine deutsche Politik gegenüber Frankreich gebe, die des Reichsaußenministers, die Herr Abetz und ich in der gleichen Weise vertreten." Wer anderes behaupte, gehöre zu jenen "geistigen Urhebern der Deutschenhetze", die auch seine Position diskreditieren wollten ${ }^{203}$. Nur Stunden später verwahrte sich Welczeck erneut gegen die "Giftmischer-Legende“, dem "gegen Abetz betriebenen Kesseltreiben nicht fern" zu stehen. Anlaß war ein Besuch des Auslandsreferenten im Stab der Deutschen Arbeitsfront, Franz Langer, der in Paris wegen eines Austausches mit französischen Berufsorganisationen verhandelt hatte. Zwei Mitarbeiter von Arbeitsminister Pomaret hatten ihm erzählt, der Botschafter sei stets gegen die von Abetz im Auftrag seines Chefs betriebene „illegale“ Diplomatie gewesen. „Da Herr Langer Verbindungsmann mit dem Büro Ribbentrop ist, will er diese ungeheuerliche Verleumdung meiner Person dort berichten", empörte sich Welczeck ${ }^{204}$. Tatsächlich schrieb Langer einen Rapport für die ,Dienststelle', der den Verdacht seiner französischen Gesprächspartner wiedergibt, Welczeck habe die "Lawine gegen Abetz ausgelöst“; als eigentlicher Repräsentant des Reiches müsse er dessen Treiben doch mit gemischten Gefühlen beobachtet haben. Auch diese Niederschrift enthält ein energisches Dementi des Botschafters, der bedauerte, daß systematisch ein Keil zwischen ihn und Abetz getrieben würde. „Welczeck schilderte mir Einzelheiten aus der herzlichen und engen Zusammenarbeit mit Herrn Abetz und versicherte mir, daß er im Gegenteil von jeher überzeugt war, daß die Tätigkeit des Herrn Abetz in Frankreich notwendig sei und viele Dinge [...] nur auf diesem Wege erledigt werden könnten, da die Botschaft sich oftmals als offizielle Stelle [...] mit diesen Aufträgen nicht beschäftigen konnte. "205

Dieses Bild kongenialer Harmonie, von Welczeck wortreich ausgeschmückt, kontrastiert auffällig mit dem Zeugnis seines Mitarbeiters Eugen Feihl, das Bonnets Angaben stützt. Pressefachmann Feihl, nach 1945 mehrfach von den Alliierten vernommen, charakterisierte das Vorkriegsverhältnis zwischen der Pariser Botschaft und Abetz als gespannt und von Konkurrenzdenken geprägt. Ihm zufolge war Abetz in der Rue de Lille "nicht eben gern gesehen“, weil er unkontrollierbar am Rande der offiziellen Beziehungen operierte, gelegentlich „sehr durch-

202 Welczeck an Auswärtiges Amt, 12. 7. 1939; ADAP, D VI, Nr. 658.

203 Welczeck an Auswärtiges Amt, 15. Juli; PA/AA, Botschaft Paris $1156 \mathrm{c}$.

204 Welczeck an Auswärtiges Amt, 15. Juli; ADAP, D VI, Nr. 676.

205 Aufzeichnung Langers über seinen „Pariser Aufenthalt“, 28. 7. 1939; PA/AA, R 27114. 
sichtig" gegen die Botschaft intrigierte, „ziemlich offen“ aus üppigen Geheimfonds schöpfte und zahlreiche Franzosen glauben machte, in weitaus stärkerem Maße als Welczeck in Berlin Gehör zu finden ${ }^{206}$. Ribbentrop persönlich habe die Rivalität geschürt und überhaupt alles getan, um die Hitler ohnehin suspekten Berufsdiplomaten zu schwächen, nicht zuletzt mit dem Ziel, möglichst rasch Minister zu werden. Die jungen Leute der ,Dienststelle', so Feihls Beobachtung, unterstützten die „primär auf Knalleffekte und propagandistische Einflußnahme“ ausgerichtete Politik ihres Chefs bereitwillig; sie brannten vor Ehrgeiz und schätzten die "vergreisten" AA-Beamten gering 207.

Feihls Wahrnehmungen zum Überlegenheitsdünkel des ,Dienststellen'-Personals, an dem sich altgediente AA-Vertreter rieben, gewinnen an Aussagekraft vor dem Hintergrund jenes Elitebewußtseins, das Ribbentrop seinen Mitarbeitern einzuimpfen pflegte. Auch Abetz gefiel sich durchaus in der Rolle des avantgardistischen "Machers"208 und hatte seit Ribbentrops Machtübernahme in der Wilhelmstraße im Februar 1938 und den schadlos überstandenen Anfeindungen heimischer Parteikreise gewiß noch an Selbstsicherheit zugelegt. War Welczeck mithin gut beraten, nach außen demonstrativ den Schulterschluß mit einem Mann zu üben, dessen Methoden ihm suspekt erschienen und den er in Wirklichkeit als Widerpart empfand? Wenngleich letzte Gewißheit fehlt, kann sich der Betrachter doch des Eindrucks kaum erwehren, daß der diplomatische Außenseiter Abetz auch bei der amtlichen deutschen Vertretung in Paris kräftig aneckte - ein Aspekt, den die Affäre vom Sommer 1939 eher beiläufig berührt, der aber einmal mehr auf die so typischen Grabenkämpfe zwischen einzelnen Institutionen und Funktionsträgern im NS-Staat verweist.

Otto Abetz, für den es nach 1945 um Kopf und Kragen ging, stilisierte sich als politisches Bauernopfer: „Die französische Regierung stand zu sehr unter dem Druck der Kriegspartei, um wünschen zu können, daß ich der Friedenspartei ihres Landes Argumente lieferte." ${ }^{209}$ Die gegen ihn erhobenen Vorwürfe nannte er „völlig aus der Luft gegriffen“, an Gehässigkeit und Unsachlichkeit kaum zu überbieten; seine Tätigkeit in Frankreich sei schlicht falsch interpretiert worden ${ }^{210}$. Den Hauptvorwurf, er habe erklärt, die Westmächte würden sich für Polen nicht schlagen, überging er geflissentlich, ebenso seine freiwillige Abreise auf Anraten Bonnets. Statt dessen behauptete er, erst nach seiner Rückkehr nach Berlin zur unerwünschten Person erklärt worden zu sein ${ }^{211}$. Dadurch konnte fälschlicherweise der Eindruck entstehen, als habe die französische Regierung seine Abwesenheit benutzt, ihm in feiger Manier die Koffer vor die Tür zu stellen. „Ehrenwörtlich“ bestritt er, vor Kriegsbeginn Gelder verteilt, Vorteile verspro-

206 Protokoll Nr. 149/2 der Sûreté Nationale vom 1. 9. 1946; AN, 3 W 358, Dossier Feihl.

207 Vgl. Abetz-Prozeß, Zeugenaussage Feihls am 19.7. 1949, pag. 43, 51, 58f.; AN, 334 AP 49. Vernehmung Feihls durch Fred Rodell am 17. 12. 1947; StA Nürnberg, KVAnklage, Interrogations, F 12.

$208 \mathrm{Vgl}$. Abetz, Das offene Problem, S. 48f.

209 Ebenda, S. 106.

210 Protokoll Nr. 204/1 vom 16.11. 1945; AN, F 7/15331. Les procès de collaboration, S. 490; Das offene Problem, S. $103 \mathrm{f}$.

211 Protokoll Nr. 204/5 vom 26. 11. 1945; AN, F 7/15331. 
chen oder gar Spionage getrieben zu haben 212. Tatsächlich war er kein Agent traditioneller Schule, doch mitnichten harmlos. Die Dienststelle Ribbentrop operierte, wie scharfsichtige Analytiker schon vor 1939 erkannten, auf vergleichsweise subtilem Niveau. Ihre Mitarbeiter wirkten bevorzugt auf intellektueller, publizistischer Ebene und gesellschaftlichem Parkett und bestärkten eher unaufdringlich jene Franzosen in ihrem Glauben und Handeln, die Deutschland aus Friedensliebe, Bolschewistenfurcht, Antisemitismus oder Bewunderung für Führerkult und Kraftmeierei entgegenkommen wollten. „Ils ont agi avec beaucoup de méthode“, resümierte im Mai 1940 das Pariser Innenministerium, „employant ici la corruption, là flattant les ambitions ou les passions partisanes, mettant à profit la naïveté ou la terreur des uns, sachant au besoin faire appel à la générosité ou à l'idéalisme des autres. " 213 Viele der Verführten, in vorderster Linie das Heer der Frontkämpfer, repräsentierten Volkes Meinung; andere waren, von der Linken enttäuscht, ins faschistische Lager abgedriftet. Etliche gehörten gehobenen, besitzenden, konservativen Kreisen an, wie die Mitgliederliste des Comité FranceAllemagne belegt und de Kerillis, dem linksinspirierter Defätismus folgerichtiger erschien, erschrocken feststellte, nicht ohne hieraus eine schwere, nur durch entschlossenes Handeln einzudämmende Krise des nationalen Bewußtseins abzuleiten ${ }^{214}$.

Die Aktivitäten eines Otto Abetz zielten mit jedem Jahr seines Wirkens kompromißloser und unzweideutiger darauf ab, in Frankreich vorhandene germanophile Strömungen auszubeuten, germanophobe zu neutralisieren. Sie reihen sich ein in eine Kette von Unternehmungen, die das innen- und außenpolitische Reaktionsvermögen der, Grande Nation' lähmen sollten und deren Protagonisten häufig unter dem unscharfen, mythentreibenden Begriff ,Fünfte Kolonne' zusammengefaßt werden. Ribbentrops Referent kam spätestens seit den geballten Anschuldigungen des Sommers 1939 nicht umhin, zur ersten Garnitur dieser Schattenarmee gezählt zu werden. „Abetz', en 1939, était devenu un nom générique“, konstatierte ein Jahrzehnt später der Militärstaatsanwalt. „Dire de quelqu'un qu'il était ,un Abetz', [...] cela voulait dire qu'il était le chef de la cinquième colonne. "215 Daß sich seine Tätigkeit, von Regierungsseite aus vermeintlicher politischer Opportunität lange Zeit toleriert, konventioneller Betrachtungsweise leicht entzog, belegt eine Studie des Quai d'Orsay vom Mai 1938 über propagandistische Umtriebe nationalsozialistischer Organisationen in Frankreich. Sie berichtet ausführlich über Strukturen und Aufgaben der Deutschen Gemeinschaft und des Deutschen Hilfsvereins, die auf Sammlung und einheitliche ideologische Ausrichtung der Auslandsdeutschen bedacht waren, der NSDAP-Landesgruppe ${ }^{216}$, der

212 Protokoll Nr. 204/3 der Sûreté Nationale vom 26. 11. 1945, „Otto Abetz et $5^{\text {ème }}$ colonne", ebenda. Abetz-Prozeß, 12. 7. 1949, pag. 19f.; AN, 334 AP 49.

213 Der Innenminister an die Präfekten, Rundschreiben „Efforts allemands pour atteindre le moral français" vom 14. 5. 1940; AN, F 7/14713.

214 "Allez-y, Daladier!" L'Epoque, 16. 7. 1939.

215 Abetz-Prozeß, Plädoyer von Capitaine Flicoteaux am 21.7. 1949, pag. 39; AN, 334 AP 49.

216 "Ce sont pour la plupart des personnes bien placées, ayant accès dans tous les milieux, qui 
systematisch Informationen aus Handel und Finanzwelt sammelnden DAF-Sektion und anderer NS-Wirtschaftsverbände sowie des Akademischen Austauschdienstes, dessen Schäflein primär nach ihrer Nützlichkeit für das Reichspropagandaministerium ausgewählt würden. Kein Wort jedoch über die Dienststelle Ribbentrop, die Deutsch-Französische Gesellschaft oder ihre französische Schwesterorganisation ${ }^{217}$.

Selbst de Kerillis, der die Gefahren einer nationalsozialistischen Unterwanderung des Landes für gewöhnlich in grellsten Farben ausmalte, rätselte gelegentlich über den realen Stellenwert des Comité France-Allemagne im „gigantischen, aber ziemlich geheimnisvollen" Räderwerk der NS-Propaganda. Nur über das Ziel hegte er keinen Zweifel: Das CFA solle, von deutscher Seite mit Illusionen und Lügen infiziert, einflußreiche Pariser Gesellschaftskreise narkotisieren und über die wahren Pläne Hitlers so lange wie nötig hinwegtäuschen. Das spezifisch Tükkische dieser Methode arbeitete er anhand eines Vergleichs mit sowjetischer Agitation heraus. Während letztere durch die Existenz einer französischen KP klar erkennbare Konturen aufweise, seien Hitler-Anhänger häufig schwieriger auszumachen. Man könne ,Munichois', Antisemit, Befürworter einer Annäherung an Deutschland und Gegner eines Bündnisses mit Moskau sein, ohne notwendigerweise im nationalsozialistischen Lager zu stehen ${ }^{218}$.

Kritisch differenzierend beurteilt die zeitgeschichtliche Forschung die Wirkung der NS-Propaganda in Frankreich. Charles Bloch hob ihren Einfluß hervor, maß aber der pazifistischen beziehungsweise antikommunistischen Grundhaltung vieler Franzosen einen insgesamt höheren Stellenwert $\mathbf{z u}^{219}$. Jean-Baptiste Duroselle stuft die Wirkung der deutschen Wühlarbeit eher noch geringer ein: „Ce n'est pas la propagande qui a créé le pacifisme [...] Ce n'est pas elle qui suscite, dans certains groupes, des réactions passionnées. “220 Er unterstreicht die tiefsitzende Furcht der Franzosen vor einem neuen Blutbad und spricht bereits im Hinblick auf die Rheinlandkrise 1936 von einem „pazifistischen Tornado“, der jeden Ansatz entschlossenen Widerstands gegen Hitlers Vorgehen hinwegfegen mußte ${ }^{221}$. Sein bezeichnendes Urteil über die französische Kriegserklärung vom September 1939 lautet: „... pour ce peuple pacifique, la guerre est une première défaite.“222 Eher zurückhaltend äußert sich auch Jean-Louis Crémieux-Brilhac: So wirkungsvoll die propagandistischen Bemühungen der Deutschen gewesen sein mochten, „on se gardera de céder rétrospectivement au mythe du complot "223. Maurice Vaïsse kommt zu dem Schluß, daß der Pazifismus im Frankreich der dreißiger Jahre län-

s'intéressent à la vie politique et économique de la France, surveillent les milieux de réfugiés allemands et ne manquent aucune occasion de faire de la propagande“.

217 Französisches Außenministerium an Botschaft London, 31. 5. 1938, mit Anlage „L'organisation national-socialiste allemande en France“; MAE, Europe 1918-1940, Allemagne 757, Bl. 84-103.

218 Wie Anm. 214.

219 Bloch, Das Dritte Reich, S. $177 \mathrm{ff}$.

220 Duroselle, La décadence, S. 209.

221 Ebenda, S. 171.

222 Ebenda, S. 493.

223 Crémieux-Brilhac, Les Français de l'an 40, I, S. 76 f. 
gere Zeit eine Politik der festen Hand beeinträchtigte und zu spät überwunden wurde, als daß seine Folgen die Landesverteidigung nicht spürbar tangiert hätten $^{224}$. Max Gallo seinerseits charakterisierte die durch Männer wie Abetz verschlechterte Ausgangslage Frankreichs zu Kriegsbeginn wie folgt: „Trop d'hommes entretenaient ou avaient entretenu des relations avec l'ennemi [...], trop d'hommes avaient été séduits par les idées fascistes ou nazies. La ,propagandec avait trop de points d'appuis et de relais [...] Il suffit de quelques grains de sable pour gripper le plus puissant des moteurs: il y avait trop de grains de sable. "225

Otto Abetz' Verleumdungsklage überholte der Krieg, der das weitere Geschehen diktierte. Erst die Kapitulation Frankreichs im Juni 1940 setzte dem Aufenthaltsverbot - zwangsläufig - ein Ende.

224 Vaisse, Der Pazifismus und die Sicherheit Frankreichs.

225 Gallo, Cinquième colonne, S. 287. 